\title{
Effects of axial and rotational restraints on concrete-filled tubular columns under fire
}

\author{
Carmen Ibañez ${ }^{\mathrm{a}}$, M.L. Romero ${ }^{\mathrm{b} *}$, Antonio Hospitaler ${ }^{\mathrm{b}}$ \\ a Departamento de Mecánica y Construcción \\ Universitat Jaume I, Castelló, Spain \\ b Instituto de Ciencia y Tecnología del Hormigón (ICITECH) \\ Universitat Politècnica de València, Spain \\ * corresponding author: mromero@mes.upv.es
}

\begin{abstract}
This paper presents a study of the effects of axial and rotational restraints on the fire response of concrete filled tubular (CFT) columns. The fiber model presented by the authors in a previous paper Ibañez et al. (2013) is employed to simulate the fire behavior of CFT columns within non-sway frames. Parametric studies are performed to analyze the influence of the different factors affecting the problem. Consequently, the opposite effects that the restraining frame has on the fire response of CFT columns are corroborated. On one hand, the restrained thermal elongation induces restraining forces which negatively affects the column. However, a beneficial effect is produced by the rotational restraint which positively modifies the boundary conditions of the heated column. Besides, another favorable effect comes from the gradual redistribution of the internal forces as the heated column loses its mechanical capacity, resulting in higher FRR. In a second step, current provisions given by Eurocode 4 Part 1.2 (EC4) are analyzed together with those given in the UK National Annex to Eurocode 4. Finally, these values are also used in the assessment of the simple calculation model presented by the authors in a previous paper Ibañez et al.
\end{abstract}


(2015) and subsequently a proposal is made obtaining reasonably accurate but slightly safe results since the guidelines of CEN-Horizontal Group Fire were followed. As a result, the fire effective length value of $0.5 \mathrm{~L}$ given by EC4 is found to lead to unsafe results, being more appropriate to adopt the value of $0.7 \mathrm{~L}$ suggested in the UK National Annex.

Keywords: Concrete filled tubular column; Axial and rotational restraints; Simple calculation method; Effective length; Non-sway frames; Eurocode 4.

\section{NOTATION}

$A / V \quad$ Section factor

CFT Concrete filled tube

D Diameter of the column

EC4 Eurocode 4 Part 1.2

FRR Fire resistance rating

$L \quad$ Length of the column

$l_{\theta} \quad$ Buckling length in the fire situation

$P / P_{0} \quad$ Restraining forces

T Temperature

UK NA UK National Annex to Eurocode 4

$t \quad$ Thickness of the steel tube

$\alpha \quad$ Stiffness ratio $\alpha=K_{\text {beam }} / K_{\text {column }}$

$\beta \quad$ Effective length ratio

$\bar{\lambda} \quad$ Relative slenderness of the column at room temperature

$\bar{\lambda}_{\theta} \quad$ Relative slenderness of the column in the fire situation

$\mu \quad$ Axial load level $\mu=N / N_{R d}$

$\xi \quad$ Relative error 


\section{INTRODUCTION}

Generally, most of the published works on the fire behavior of CFT columns deal with the study of these columns as isolated members. Without restraints, their general fire response can be divided into the four stages displayed in Fig. 1 in terms of column axial displacement along time [1][3]. At the first phase of a fire, the steel tube expands faster than the concrete core due to its higher thermal conductivity and its direct exposure to fire and, as a result, the axial displacement rate of both components is decoupled. Owing to this fact, the axial load ratio of the steel tube progressively increases, up to a point where the whole applied load is supported uniquely by the steel tube (stage 1). When it reaches its critical temperature and the local yielding of the steel section occurs (stage 2), it starts to shorten, allowing the loading plate to contact back the concrete core. At this point, the axial force ratio undergoes an inversion since the load sustained by the steel tube is gradually transferred to the concrete core as the column shortens (stage 3). In previous stages, the steel tube has lost its load-bearing capacity and now the concrete core is the element showing more resistance. The ultimate failure occurs when the concrete core completely loses its strength and stiffness after a significant period of time during which its mechanical properties are completely degraded (stage 4).

However, the behavior of a column within a structure differs from that shown as an isolated member and this is even more noticeable at high temperature, where the increment in the column relative stiffness to the adjacent non-exposed structural members leads to changes not only in its boundary conditions but also in its loading conditions, modifying its response. Therefore, and taking into account the characteristic fire behavior of CFT columns presented above, the study of the effects of axial and rotational restraints becomes crucial to completely understand the response of these composite columns when they are assembled to other structural members. 
In this line, some attempts have been done ([4], [5], [6]), although the number of studies in the field of CFT columns is still scarce in comparison with the number of publications on steel structures ([7], [8], [9], [10], [11], [12]). Among the most relevant works, the global model presented by Wang [4] can be found to evaluate the effects of structural continuity on the fire resistance of CFT columns by a finite element program developed by the authors. According to Wang [4], given the uniform reduction of the crosssectional stiffness in steel columns, in fire limit state, the structural continuity should provide built-in conditions and should reduce bending moments to a negligible level since the bending stiffness at elevated temperatures is very low. However, the author pointed out that it may be not the case of CFT columns where the temperature distribution in the composite cross-section is non-uniform. A numerical study was carried out to assess the provision for the effective length of composite columns in the fire limit state given by Eurocode 4 Part 1.2 [13] which currently has a value of $0.5 \mathrm{~L}$ for columns placed at an intermediate story. As reported by the author, its applicability for CFT columns was confirmed.

In the same vein, Bailey [5] also presented a fiber beam model for simulating square CFT columns at room and high temperatures. The work focused on the evaluation of the effective length at fire limit state of these composite columns and it was concluded that for columns continuous at both ends the adoption of an effective length of $0.75 \mathrm{~L}$ was recommended to obtain safe predictions.

The two works mentioned above employed fiber beam models since they are the most efficient from the computational point of view when part of a structure, and not only a single element, is modeled. Although using fiber beam models may imply assuming some simplifications, the improvement in the response given by more realistic models usually does not compensate the increase in the computational cost associated. 
However, some studies can be found where three-dimensional finite element models have been employed despite of their elevated computing time. Thus, Yu et al. [6] developed a three-dimensional model in ABAQUS for circular CFT columns but, in order to maximize the efficiency of the numerical procedure with acceptable loss of accuracy, simplifications such as neglecting the slip and separation between the steel tube and the concrete core were adopted. Only the CFT column was heated and the rest of the structural elements were not exposed to fire. The authors highlighted two aspects to be considered in fire design: due to the redistribution of internal forces, the bending moment in the heated column was significantly reduced and the FRR of the column within a frame was improved.

Hence, given the limited number of research studies dealing with the fire behavior of CFT columns within frames, this paper presents a new model for the study of the effects of axial and rotational restraints on the fire response of columns with continuity at both ends.

In this work, an extensive parametric analysis of the fire response of CFT columns within frames and continuous at their both ends is carried out. For that purpose, a validated fiber beam model previously developed by the authors [1] is employed. The subsequent study of the results is presented jointly with the evaluation of the provisions given by Eurocode 4 Part 1.2 [13]. Finally, the assessment of a simple calculation method proposed by the authors in a previous publication [2] is included and the corresponding proposal for the effective length in fire is given.

\section{DESCRIPTION OF THE NUMERICAL MODEL}

A previously validated fiber beam numerical model developed by the authors [1] is available. For the sake of simplicity, just a brief description of the model is given hereafter since it is not the purpose of this paper. 
The finite element model takes as a basis the FedeasLab [14] platform, a Matlab toolbox for the nonlinear analysis of structures. This model is capable of simulating with enough accuracy the fire behavior of concentric axially loaded concrete filled tubular columns. The details of the model are described in [1] jointly with its validation against results from own experiments and from tests found in literature. The validity of the model covers a wide range of concrete infill: plain, bar reinforced and steel fiber reinforced concrete of both normal and high strength.

By means of the numerical model, a sequentially coupled thermal-stress analysis can be performed where two analysis steps are differenced: a thermal analysis and a mechanical analysis. First, a sectional thermal analysis is carried out to compute the temperature field of the columns and subsequently, a mechanical problem is solved to obtain the structural response.

For the main heat transfer parameters, the values recommended in EN 1991-1-2 [15] are used. The standard ISO-834 [16] fire curve is applied to the exposed surface of the CFT column along its whole length as a thermal load, through the convection and radiation heat transfer mechanisms. The thermal resistance at the steel-concrete interface is taken into account through a gap conductance value of $200 \mathrm{~W} / \mathrm{m}^{2} \mathrm{~K}$, as recommended by other authors [3] [17]. The effect of concrete moisture is considered assuming that during the process of water evaporation, which starts when the temperature reaches $100^{\circ} \mathrm{C}$, the concrete temperature does not increase since all the heat provided is employed in this process until the moisture has evaporated completely.

The fiber beam model consists of three parts: the concrete core, the steel tube and the link elements, which connect the former two. It is based on the clear differentiation of phases discussed in the previous section and in the simulation of the existing relative 
sliding between the steel tube and the concrete core, since this interaction mechanism is the main phenomenon responsible for the bearing capacity of the column.

Therefore, in the model, a complete circular CFT column is formed by assembling in parallel two simple columns: a steel hollow section column and a concrete column. These columns are modeled with fiber finite elements connected at their nodes by link elements both longitudinally and transversely as shown in Fig. 2. Transversal link elements have a high stiffness to assure identical deformed shapes. However, the longitudinal link elements are designed in such a way that the top longitudinal link shows an elevated rigidity under compression but zero stiffness when in tensions. The inner longitudinal links reproduce the marginal friction between the steel tube and the concrete core. The axial load is applied to the top node and maintained constant during the fire history.

The fiber beam-column element employed to model the two simple columns has a corotational formulation with a mixed interpolation iterative scheme [18]. After a sensitivity analysis, the number of elements per column was set to four since it proved to give high accuracy in the results [1]. In Fig. 2, the cross-sectional discretization pattern adopted after the calibration procedure is also shown, which divides the section into a regular array of fibers in both radial and circumferential directions.

The value adopted for the out-of-straightness of the column was L/1000, since it has proved to give accurate results in other models existing in literature [3] and it is the value normally employed by the majority of researchers.

In the case of CFT columns with normal strength concrete as infill, the constitutive model for elevated temperatures proposed by Lie [19] was the one which best fitted the experimental results in comparison with the mechanical model included in EN 1992-1-2 [20] which proved to produce safer results [1] [3]. The thermal properties for concrete were taken from EN 1992-1-2 [20], except for the thermal expansion coefficient, which was 
given a value of $\alpha_{c}=6 \times 10^{-6}{ }^{\circ} \mathrm{C}$ as recommended in other publications [3] [22] and verified by the authors [1]. For structural steel, the temperature dependent thermal and mechanical properties recommended in EN 1993-1-2 [21] were adopted.

Given the existing sliding and separation between the steel tube and the concrete core produced by their different thermal expansion coefficients, the confinement of the concrete is not taken into account in the mechanical analysis in the fire situation covered in this study.

\section{DESCRIPTION OF THE SUBFRAME EMPLOYED}

The effects of structural continuity on the fire behavior of a column within a frame can be classified into two opposite groups (positive and negative). On the one hand, the action of the surrounding structure in the heated column has a positive effect coming from the increment in the rotational restraint to the column resulting in a reduction of its effective length and the consequent improvement of its load bearing capacity. Besides, when the CFT column mechanical properties are highly degraded, new redistribution paths appear and part of the applied load is gradually transferred to the adjacent beams thus increasing the fire resistance time of the column. On the other hand, the axial restraint to the thermal elongation of the column affects it negatively since it induces restraining forces to the member and thus increases the load supported by the column.

In this work, the axial and rotational restraints are considered acting simultaneously with the aim of reproducing the actual fire situation where the thermal elongation and the bowing of the heated column are limited at the same time. Thus, due to the increment in the relative rigidity of the surrounding non heated structure with respect to the heated column, the stiffness of the joint connecting the column to the rest of the elements is affected and, 
therefore, both its axial stiffness (i.e. the axial force required to produce a unit elongation) and its bending stiffness (i.e. the moment required to produce a unit rotation) increase.

The mechanical analysis of a frame involving a concrete filled tubular column in fire would require an elevated computational cost given the multitude of elements implicated and the nonlinearities associated to the analysis of the fire response of a CFT column in fire. However, the previously described fiber beam model presents a substantially lower computing time which makes it a suitable analysis tool to carry out this type of studies with a reduced computational cost.

The effects of the axial and rotational restraints on the fire behavior of CFT columns were studied by means of the subframe model shown in Fig. 3. In this work, the structural continuity of an intermediate column was uniquely analyzed. The subframe is formed by three continuous circular CFT columns which are connected to their corresponding beams at their ends. It is a non-sway frame where the external ends of the beams are modeled as fixed, providing the highest level of restriction to the column. The CFT columns are simulated according to the validated model described in the previous section. The adjacent beams are modeled by means of beam elements with linear elastic material in order to simplify and accelerate the calculation procedure.

The intermediate column is the member subjected to fire while the rest of the structural members remain unheated. This corresponds to one of the potentially most severe situations where the fire action is just affecting a part of the structure. Note that if the subframe consisted of more spans and all the columns were heated following the same fire curve, the detrimental effect of the restrained thermal elongation could not be studied and the observed resultant effect would always be positive. 


\section{CONSIDERATIONS OF FIRE EFFECTIVE LENGTH IN EUROCODE 4}

With regard to composite columns in buildings, Eurocode 4 Part 1.2 [13] considers the influence of the structural continuity in fire design by means of a reduction in the effective length of the columns. Thus, according to Fig. 4 , a value of $0.5 \mathrm{~L}$ is recommended for the effective length in the case of a composite column placed in an intermediate story (continuous at both ends), whereas for a column continuous at one end only (top story), a value of $0.7 \mathrm{~L}$ is suggested ( $\mathrm{L}$ is the system length). These recommendations coincide with those proposed for steel frames in Eurocode 3 Part 1.2 [21], which means that no specific recommendations exist depending on the type of column.

The adoption of these assumptions in the fire design of CFT columns has been an issue of discussion for researchers in the last decade [4] [5]. In steel columns, the profile of the column exposed to fire heats uniformly and rapidly so that the column stiffness reduces in the same way. Therefore, in this case, assuming fixed ends for the column $(0.5 \mathrm{~L})$ can be acceptable since the ratio between the fire exposed column stiffness and the unheated surrounding structure is considerably low. Nevertheless, in CFT columns the crosssectional temperature field is clearly non-uniform which, together with the relative sliding appearing between the steel tube and the concrete core, can lead to a different behavior and the guidelines of Eurocode 4 Part 1.2 can produce unsafe results.

In fact, following these lines, in the UK National Annex to Eurocode 4 Part 1.2 (UK NA), the buckling factors of 0.5 and 0.7 have been conservatively increased to 0.7 and 0.85 respectively [23].

\section{PARAMETRIC ANALYSIS}

A parametric analysis was carried out by means of the frame presented above. The parameters affecting the fire resistance included in the study were the outer diameter of the 
column $(D)$, the thickness of the steel tube $(t)$, the relative slenderness of the column at room temperature $(\bar{\lambda})$, the applied load level $(\mu)$ and the stiffness ratio between the stiffness of the adjacent beams and the exposed column at room temperature $(\alpha)$. This last parameter is calculated as follows:

$$
\alpha=K_{\text {beam }} / K_{\text {column }}
$$

where $K=E I / L$ for the corresponding member. Note that this value just serves as a reference of the level of rigidity of the surrounding beams with respect to the initial state of the column. This parameter was also employed by Gomes et al. [9] in the design of their numerical studies on the buckling length of steel columns within frames.

In Table 1, a summary of the parameters studied is presented. For the stiffness ratio $(\alpha)$, the values of $0.1,0.5,1$ and 2 were selected, ranging from the configuration for which the column stiffness is 10 times that of the beams to the case in which the beams are two times more rigid than the column. Three levels of applied load were evaluated: $0.3,0.5$ and 0.7 , defined as the ratio with respect to the resistance of the column in axial compression at room temperature. Although the level of 0.7 may be less usual in daily practice, it was included in order to cover a wider range. All the columns were studied under concentric loads according to the limits of application of the numerical model developed. However, this cannot be considered as a limitation of the study since previous theoretical analysis of this issue [4] proved that at the fire limit state both slender and short columns may be assumed to resist only axial loads given the reductions in the bending stiffness of the column.

In total, 360 frames were analyzed where the beams were $5000 \mathrm{~mm}$ long, which is a span value commonly found in practice. They were modeled with a European normalized I section IPE300 and their stiffness (EI) was incremented linearly. Note that in this analysis, each column studied is identified as follows: CXXX-T-L-S (i.e. C193-5-9010-2), where C 
stands for circular, XXX represents the outer diameter in $\mathrm{mm}$, T the thickness in $\mathrm{mm}$, $\mathrm{L}$ the column length in $\mathrm{mm}$ and $\mathrm{S}$ the relative slenderness. This identification is followed by the corresponding information about the load level and the stiffness ratio.

With the aim of comparing the results with those produced by Eurocode 4 guidelines, the material properties adopted in the parametric studies were those included in the European code. Thus, for the steel tube, the thermal and mechanical properties of Eurocode 3 Part 1.2 were assumed [21] and for the concrete core the expressions proposed by Eurocode 2 Part 1.2 were used [20]. For all the columns the yield strength assumed for the steel tube was $355 \mathrm{MPa}$ and a nominal compressive strength of $30 \mathrm{MPa}$ was assigned to the concrete core.

\section{ANALYSIS OF THE RESULTS}

\subsection{FIRE RESPONSE OF CFT COLUMNS WITIHIN FRAMES}

From the analysis performed, the response of each member was registered as shown in Fig. 5, where the results obtained for the specimen C193-5-1351-0.3 are presented. This column has an external diameter of $193.7 \mathrm{~mm}$, a steel tube thickness of $5 \mathrm{~mm}$ and a relative slenderness of the column of 0.3 . This response corresponds to the simulation of the column within a frame with a moderate stiffness ratio $\alpha=0.5$ and under a load level $\mu=0.3$.

Different types of results were employed to draw conclusions regarding the influence of the parameters studied. On the one hand, the evolution along time of the fire response of the columns in terms of axial displacement (Fig. 5a), axial force ratio (Fig. 5c) and restraining forces was obtained (Fig. 5b). The latter was defined as the relation between the absolute load of the column and the initial applied load $\left(P / P_{0}\right)$ as can be observed in Fig. $5 b$, where the fire response of one of the specimens analyzed is shown. 
The restraining forces (Fig. 5b) evolution is similar to that observed for the axial displacement (Fig. 5a) of the column since they appear when the surrounding structure opposes its thermal elongation. These forces increase up to a maximum value and then decrease due to the loss of strength of the steel tube recovering the initial value of the applied load.

On the other hand, results in the form of single values were also registered. Two of these values were the time of fire resistance (FRR) and the column force at failure which corresponds to the axial buckling resistance of the column obtained by the numerical model $\left(N_{f i, R d, M O D E L}\right)$.

Another meaningful point was the time at which the restraining forces reached the initial value of the applied load (Fig. 5b), hereafter denominated as critical time according to Pires et al.[24].

As exposed before, the effect of the surrounding structure on the fire response of a CFT column can be separated into a beneficial action given by the rotational restraint and a detrimental effect generated by the axial restraint. Nevertheless, the global effect on the fire behavior of the columns can be studied by means of the comparison of the column force at failure and the initial applied load.

In Fig. 6 it can be observed that, generally, the axial force of the column at failure is less than the applied load, which represents a global positive effect that, normally, grows with the increment in the stiffness ratio. At the final stages of a fire, when the column degradation state is advanced, the transference of load from the column to the surrounding frame becomes enhanced which relieves the stress state of the column and increases its FRR. Gradual load redistribution is more likely to occur in specimens with low slenderness, whose failure usually is not premature and their responses reach the last stages of a fire. 
Note that Fig. 6c and Fig. 6d are enlarged views of the shaded areas of Fig. 6a and Fig. 6b respectively.

In those CFT columns having low slenderness and presenting a higher $\mathrm{D} / \mathrm{t}$ ratio, the role of the concrete core becomes very important at the final stages of a fire. Thus, the fire response is highly influenced by this material which is protected by the steel tube and degrades slowly. Besides, the concrete core contributes to resist the load and, during this period, the behavior becomes more ductile. Thus, the action of the frame at the last stages of the fire is enhanced and the load is gradually transferred to the surrounding members as the concrete core slowly degrades with the increment of its temperature.

This typical behavior can be observed for the specimen in Fig. 5. Together with the curves of the column within the frame, the fire response of the same column simulated as pinned-pinned is plotted as a reference. It can be observed that the maximum axial displacement achieved by the isolated P-P column is slightly bigger than that reached by the assembled column due to the axial restraint. In Fig. 5c, a deviation between the paths described by the two columns can be identified. This subtle change in the slope starts at a critical time, when $\mathrm{P} / \mathrm{P}_{0}$ becomes less than 1 , which means that the load is redistributed within the frame and the CFT column is released from part of the load. Thus, the negative effect created by the axial restraint is compensated, resulting in a considerable increment in the FRR. This observation confirms that assembling a CFT column to other structural members not only modifies the boundary conditions but also the loading conditions.

The different behavior of a CFT column within a frame with respect to its corresponding isolated P-P column becomes more obvious for the column showed in Fig. 7. This specimen has the same sectional properties than that in Fig. 5 but with a relative slenderness of 2 . In this case, the contribution of the frame in preventing the premature failure of the column can be observed in Fig. 7a, where the response of the column within 
the frame gets over the point where the isolated P-P column failed, allowing the column to work during a longer period of time.

This behavior may due to the fact that, although during this stage the column is negatively affected by the restraining forces and the load supported increases by more than $20 \%$ (maximum value of $\mathrm{P} / \mathrm{P}_{0}=1.26$ in Fig. $7 \mathrm{~b}$ ), the boundary conditions are changing due to the increment in the stiffness ratio which retains the column and improves its buckling behavior.

In addition, a beneficial effect can be also observed from the moment when the load supported by the composite column becomes less than that initially applied $\left(\mathrm{P} / \mathrm{P}_{0}<1\right)$. From this point on, the redistribution of the load within the frame becomes relevant. In Fig. 7c, the theoretical evolution of the concrete core axial force ratio without the action of the unheated frame is traced. This evolution has the same shape but an inverse slope than that described by the steel tube, which is the commonly observed behavior on isolated columns so that the sum of the contribution of the two components is the total amount of the applied load. However, in this case, the obtained evolution of the concrete core axial force ratio differs substantially from the theoretical one. The area enclosed by the two curves (shaded) corresponds to the percentage of load transferred from the CFT column to the frame.

A third type of response of CFT columns within frames was detected where the failure occurs during the stage in which the CFT column is supporting more load than that initially applied $\left(\mathrm{P} / \mathrm{P}_{0}>1\right)$. The columns associated to this behavior can be identified in Fig. 6 , at the bottom part of the graphs. This response was detected in slender columns and becomes more noticeable as the stiffness ratio and the load level increase. In this study, this response is particularly notable in those columns having high slenderness and showing lower D/t ratios (C273-16, C508-16). Given the thickness of the steel tube, it attracts an initially high percentage of load. When the steel tube contracts, the concrete core still 
possesses an elevated level of stiffness due to the delay in its heating caused by the combined action of its outer size and thicker steel tube. For these columns, the beneficial effect of the frame creating new paths to sustain the applied load and thus extending the duration of the column and assuring a soft failure does not occur

\subsection{INFLUENCE OF THE PARAMETERS STUDIED}

\subsubsection{Influence of the load level}

For each combination of stiffness ratio $(\alpha)$, three load levels $(\mu)$ were applied to each column. In Fig. 8a and Fig. 8b the evolution of the restraining forces is shown for two of the specimens studied which represent extreme cases of the stiffness ratio values. It is observed that for both columns the increment in the load level leads logically to a reduction in the FRR.

A low load level leads to higher values of the maximum $\mathrm{P} / \mathrm{P}_{0}$ (and, in consequence, of the maximum axial displacement) since the action of the thermal expansion counteracts the contraction of the loaded member.

Thus, in the case of specimen C139-3-4841-1.5 within a frame characterized by a stiffness ratio of $\alpha=2$ (Fig. 8a), the maximum value of the restraining forces is 1.31 for a load level $\mu=0.3$, whereas the maximum value of $\mathrm{P} / \mathrm{P}_{0}$ for $\mu=0.7$ is 1.08 which means a variation of $\mathrm{P} / \mathrm{P}_{0}$ from $31 \%$ to $8 \%$. However, for the column C323-6-3705-0.5 (Fig. 8b) within a frame with a low stiffness ratio $\alpha=0.1$ (i.e. the column is more rigid than the adjacent beams), the maximum increment in the supported load is $1.7 \%\left(\mathrm{P} / \mathrm{P}_{0}=1.017\right)$ for an elevated load level $\mu=0.7$ and $0.1 \%\left(\mathrm{P} / \mathrm{P}_{0}=1.001\right)$ for the case with $\mu=0.3$. Although both are marginal values due to the low rigidity of the frame, the trend is the same observed in the other specimen. 
The beneficial action of the frame is enhanced under lower load levels since in those cases the steel tube is not likely to fail prematurely and contacts back the concrete core thus allowing for the redistribution of internal forces.

With regard to the critical time (i.e. $\mathrm{P}=\mathrm{P}_{0}$ ), it decreases with an increment in the load level. As expected, if the steel tube is supporting high loads when it tries to expand and separate from the concrete core, its thermal expansion is not enough to counteract the contraction generated by the axial load. Therefore, the steel tube starts to contract earlier resulting in lower critical times.

Note that in those cases where the steel tube fails before contacting back the concrete core $\left(\mathrm{P} / \mathrm{P}_{0}>1\right)$, the concept of critical time becomes meaningless.

\subsubsection{Influence of the stiffness ratio}

Four different levels of stiffness ratio were employed in the study. In Fig. 8c and Fig. $8 \mathrm{~d}$ the evolution of the restraining forces along time is shown. An increment in the stiffness ratio leads to higher values of the maximum $\mathrm{P} / \mathrm{P}_{0}$ and, as a consequence, the maximum value of the axial displacement is lower.

With respect to the FRR, it is higher for those columns within very rigid frames, since the beneficial effects of the rotational restraint grow with the stiffness of the frame. For those specimens in which the critical time is achieved and the frame absorbs part of the load, it is observed that for higher stiffness ratio values this effect is more noticeable since, as expected, the redistribution capacity of the frame is more elevated.

Finally, regarding the critical time, it can be noticed that it does not vary with the stiffness ratio for one particular column under the same load level. This may be explained by the fact that until this point the beneficial and detrimental effects of the restraining frames compensate each other. This fact was already observed by Pires et al. [24] after performing an experimental program on restrained CFT columns under fire. 


\subsection{EVALUATION OF THE EFFECTIVE LENGTH}

Since the design of a column for the fire situation is a task usually accomplished for isolated columns, the way in which the change in the boundary conditions could be incorporated in the design is a determinant aspect investigated in the last decade in the field of CFT columns. As presented before, Eurocode 4 Part 1.2 [13] recommends a fire effective length of $0.5 \mathrm{~L}$ for intermediate columns (which are the type of columns covered in this work) whereas the UK National Annex recommended a value of $0.7 \mathrm{~L}$ in order to be more conservative.

Given that there is no a unified criterion regarding the effective length ratio $(\beta)$ in fire, a new comparison is presented in this section with the data generated in the previous parametric analysis. The FRR obtained when the different columns were simulated within the frame is compared with the FRR obtained by the corresponding isolated P-P columns but assuming different effective lengths. In Fig. 9 the comparison is shown for the different values of stiffness ratio considered in the parametric analysis. The effective length ratio coefficients used for comparison were 0.7 and 0.5 since they are the ones currently considered by practitioners.

For the specimens with low slenderness which are those which usually present higher values of the FRR, the assumption of 0.5 or 0.7 gives safe results. However, for more slender columns $(\bar{\lambda}=1 ; 1.5 ; 2)$ with lower values of the FRR, unsafe cases are registered if a value of $0.5 \mathrm{~L}$ is adopted for the fire effective length. Therefore, a general value of $0.7 \mathrm{~L}$ could be used in simulations to avoid unsafe results. 


\section{ANALYSIS OF CURRENT EUROCODE 4 GUIDELINES}

The buckling fire resistance of the columns within frames included in the parametric analysis was computed by means of the general method of Eurocode 4 Part 1.2 Clause 4.3.5.1 [13] for each of the effective length coefficients presented above $(\beta=0.5$ and $\beta=0.7)$.

\subsection{COMPARISON WITH EFFECTIVE LENGTH CONSIDERATIONS IN EUROCODE 4}

The application of the general principles in Clause 4.3.5.1 of Eurocode 4 [13] to CFT columns requires the adoption of a set of flexural stiffness coefficients $\left(\varphi_{\mathrm{i} . \theta}\right)$. Authors such as Espinos et al. [25] have worked on the proper definition of these coefficients since the predictions obtained when adopting a value of 1 tend to be unsafe. However, given the lack of agreement on their specific values, in this comparison they are assumed equal as unity since it is the default value used in daily practice by designers [26].

In Fig. 10a, the fire buckling resistance obtained by applying the general method of Eurocode 4 with an effective length ratio $\beta=0.5$ are plotted against the results given by the numerical simulations of the frames. It can be observed that his combination generally leads to unsafe results.

As it can be observed in Fig. 11a, where the relative error is plotted, the results obtained by Eurocode 4 with $0.5 \mathrm{~L}$ show reasonable accuracy for specimens with low slenderness $(\bar{\lambda}=0.3$ and $\bar{\lambda}=0.5)$ and all the points lie in the $\pm 15 \%$ limits. However, as the relative slenderness of the columns increases, the number of unsafe cases lying beyond the $15 \%$ boundary also augments. For this case, the mean obtained is unsafe and has a value of 0.91 (standard deviation $\sigma=0.17$ ).

Note that the relative error is calculated by:

$\xi_{N, f i}=1-\frac{N_{f i, R d, P R E D I C T E D}-N_{f i, R d, M O D E L}}{N_{f i, R d, M O D E L}}$ 


\subsection{COMPARISON WITH EFFECTIVE LENGTH CONSIDERATIONS IN UK NATIONAL}

\section{ANNEX TO EUROCODE 4}

The fire effective length of $0.7 \mathrm{~L}$ for specimens continuous at their both ends recommended in the UK National Annex to Eurocode 4 [22] was adopted to apply the general method of EN 1994-1-2 Clause 4.3.5.1.

The calculated values of the fire buckling resistance are compared to those given by the frame model in Fig. 10b. In this case, the value of $0.7 \mathrm{~L}$ produces safe results for all the cases and there are no points located outside the $15 \%$ limit on the unsafe side.

In this case, the improvement in the predictions may be explained by the fact that the tendency of the EC4 general method of producing unsafe results when stiffness flexural reduction coefficients equal to 1 are employed is compensated by the use of a more conservative fire effective length. The conservative character of the predictions calculated with $0.7 \mathrm{~L}$ can also be checked in Fig. $11 \mathrm{~b}$ where the relative error is plotted. For this comparison, the mean is clearly safe, with a value of 1.20 (standard deviation $\sigma=0.17$ ).

\section{PROPOSED SIMPLE CALCULATION MODEL FOR UNREINFORCED CIRCULAR CFT COLUMNS}

Given the tools available nowadays, a recent trend in the design of structures focuses on the employment of advanced calculation models contemplated also by the current standard codes, where the complete definition of the boundary conditions of each member and, therefore, of its effective length, is not needed.

However, the development of simple calculation models or proposals for CFT columns which facilitate the design procedure may promote their inclusion in new structures and prevent practitioners from desisting in their intention of using CFT columns and turning into typical structural elements. The method proposed in this paper, which 
seeks this aim, is developed based on a model for columns in composite braced frames fully connected to the column above and below where each story is considered as a fire compartment and thus its application is limited to columns in this situation.

In the case of members with a different structural scheme where boundary conditions are not easily identified, such as long-span arch bridges where CFT members are commonly used, this method is not applicable.

\subsection{REVIEW OF THE PROPOSED SIMPLE CALCULATION MODEL}

A method was proposed in a previous paper [2] which permits evaluating the fire resistance of unreinforced CFT columns of circular cross-section. Again, a brief review of this method is given next for a better understanding of the reader.

\subsubsection{Equivalent concrete core cross-section at room temperature}

The proposed approach is based on the concept of the equivalent concrete core crosssection at room temperature, defined as the concrete core cross-section whose contribution to the buckling fire resistance of a CFT column is equivalent to the influence of the original concrete core cross-section subjected to the corresponding temperature field, Fig. 12. The external tube maintains its initial dimension and is made of a material representing the actual degraded steel for the given fire exposure time. The calculation method proposed follows the general rules of the simplified method of Clause 6.7.3 of EN 1994-1-1 [27] for the design of composite columns at room temperature.

The first part of the simple model consists of a set of expressions for evaluating the steel tube temperature at a certain fire exposure time:

$$
\begin{aligned}
& \theta_{a}=\theta_{\text {room }}+\Delta \theta_{a}=\theta_{\text {room }}+\theta_{f} \cdot \eta_{s} \cdot \eta_{a} \nless \theta_{\text {room }} \\
& \theta_{f}=345 \log (8 R+1) \\
& \eta_{s}=1-3.38 R^{-0.18}
\end{aligned}
$$


$\eta_{a}=1-\left[0.155 R^{0.58}+t^{-0.1}\right]$

and an expression for computing the radius of the equivalent concrete core cross-section for a given time of fire exposure:

$$
r_{c, e q}=r_{\text {int }}+23\left(\frac{A}{V}\right)^{-0.01}-10 R^{0.45} \nless 0
$$

where $\mathrm{R}$ is the fire exposure time in minutes; $\mathrm{t}$ is the steel tube wall thickness in $\mathrm{mm} ; r_{\text {int }}$ is the concrete core radius in $\mathrm{mm}$; and $\mathrm{r}$ is the radius in $\mathrm{mm}$ which indicates the position in the concrete core where the temperature is calculated.

More details about the development of these equations are available in [2].

As it can be observed in Fig. 12, in the method proposed, the plastic resistance to axial compression of the section in the fire situation is calculated as follows:

$$
N_{f i, p l, R d}=A_{a} \cdot f_{a, \theta}+A_{c, e q} \cdot f_{c}
$$

and the effective flexural stiffness is obtained:

$$
(E I)_{f i, e f f}=E_{a, \theta} \cdot I_{a}+K_{e} \cdot E_{c} \cdot I_{c, e q}
$$

where $A_{a}$ and $I_{a}$ are the area and second moment of area respectively of the steel tube cross-section; $f_{a, \theta}$ is the steel strength at the temperature $\theta ; E_{a, \theta}$ is the modulus of elasticity of steel at the temperature $\theta ; A_{c, e q}$ and $I_{c, e q}$ are the equivalent area and equivalent second moment of area correspondingly of the concrete core cross-section; $f_{c}$ is the concrete strength at room temperature; $K_{e}$ is a correction factor that should be taken as 0.6 ; and $E_{c}$ is the secant modulus of concrete at room temperature.

\subsubsection{Buckling correction factor}

In the calculation model proposed, the value of the fire resistance of a CFT column in axial compression is calculated as follows:

$$
N_{f i, R d}=\eta_{\text {buckling }} \cdot \chi \cdot N_{f i, p l, R d}
$$


where $\chi$ is the reduction coefficient for the relevant buckling mode given in EN 1994-1-1 [27], which in this case corresponds to buckling curve "a"; and $\eta_{\text {buckling }}$ is the buckling correction factor to account for the influence of second orders effects at high temperatures. As it can be observed, the simple method proposed employs the buckling curve "a" for calculation.

The buckling correction factor is dependent on the different geometrical variables $\left(l_{\theta} / D, A / V, D / t\right)$ that play an important role in this problem. Therefore, an expression which is a function of the different variables was proposed. The equation is composed by the product of three partial coefficients:

$$
\eta_{\text {buckling }}=\eta_{l_{\theta} / D} \cdot \eta_{A / V} \cdot \eta_{D / t}
$$

Two sets of expressions for the buckling correction factor were defined: one for the specimens with $\bar{\lambda} \leq 0.5$ and another one for the cases with $\bar{\lambda}>0.5$.

For cases with $\bar{\lambda} \leq 0.5$ (stub columns):

$$
\begin{aligned}
& \eta_{l_{\theta} / D}=\left[-4.16+4.208 \cdot\left(l_{\theta} / D\right)^{-0.003}\right] \\
& \eta_{A / V}=\left[0.13+9.8 \cdot(A / V)^{1.6}\right] \\
& \eta_{D / t}=\left[266+0.26 \cdot(D / t)^{1.5}\right]
\end{aligned}
$$

For cases with $\bar{\lambda}>0.5$ (slender columns):

$$
\begin{aligned}
& \eta_{l_{\theta} / D}=\left[0.72+0.008 \cdot\left(l_{\theta} / D\right)^{1.322}\right] \\
& \eta_{A / V}=\left[0.67+7.4 \cdot(A / V)^{1.81}\right] \\
& \eta_{D / t}=\left[0.52+0.11 \cdot(D / t)^{-0.03}\right]
\end{aligned}
$$

\subsubsection{Summary of the proposed method}

An overview of the proposed method is given next: 
1. Set the value of the effective length of the column $l_{\theta}$ and determine the section factor $A / V$ and the $\mathrm{D} / \mathrm{t}$ ratio.

2. Calculate the steel tube temperature $\theta_{a}$ and the radius of the equivalent concrete core cross-section $r_{c, \text { eq. }}$

3. Obtain the cross-sectional plastic resistance and the effective flexural stiffness using the temperature dependent steel mechanical properties from EN 1993-1-2 [21].

4. Compute the Euler buckling load and the relative slenderness in fire.

5. Calculate the buckling reduction coefficient from buckling curve "a" as it is indicated in EN 1994-1-1 [27].

6. Calculate the buckling correction factor.

7. Obtain the axial buckling load in the fire situation.

\subsection{ASSESSMENT OF THE PROPOSED METHOD}

The assessment of the proposed method for predicting the fire buckling resistance of CFT columns within frames was accomplished. As in the previous section, the effective lengths of $0.5 \mathrm{~L}$ and $0.7 \mathrm{~L}$ were used in comparison.

In order to evaluate the accuracy of the different methods, the approach for the assessment of the accuracy of simplified methods proposed by the CEN-Horizontal Group [28] was employed. The mentioned assessment method set the next criteria to check the acceptability of a simplified method:

- Calculation results shall not be on the unsafe side by more than the $15 \%$ of the reference value.

- A maximum of $20 \%$ of the individual calculation results shall be on the unsafe side.

- The mean value of all percentage differences shall be on the safe side. 


\subsubsection{Proposed method predictions with $0.5 \mathrm{~L}$}

Predictions of the buckling fire resistance given by the method proposed adopting an effective length of $0.5 \mathrm{~L}$ were compared with numerical simulations in Fig. 10c. It can be seen that the mean has a value close to unity, $\mu=1.10(\sigma=0.18)$, since the opposite tendencies observed in Fig. 11c compensate each other. According to Fig. 11c, a value of the effective length of $0.5 \mathrm{~L}$ together with the proposed method leads to unsafe results for stub specimens whereas the predictions are considerably safer for higher slenderness. Since the proposed method is based on a set of equations which is a function of the relative slenderness at room temperature, the influence of this aspect is now detected in these results.

\subsubsection{Proposed method predictions with $0.7 \mathrm{~L}$}

The same procedure was followed to assess the accuracy of the proposed method with an effective length of $0.7 \mathrm{~L}$. A comparison of the results produced by the proposed method with the values given by the numerical simulations for the buckling fire resistance is shown in Fig. 10d where it can be observed that assuming $0.7 \mathrm{~L}$ leads to safe results. These observations can be corroborated in Fig. 11d where the relative errors are shown. Predictions show reasonable accuracy for specimens with low slenderness. For those specimens with high values of the relative slenderness taking $0.7 \mathrm{~L}$ for the effective length in fire is considerably safe with a mean value of 1.42 (standard deviation $\sigma=0.26$ ). This excessive level of safety is due to the conservative criteria set by CEN-Horizontal Group Fire [28].

\subsection{PROPOSAL FOR THE FIRE EFFECTIVE LENGTH}

After a deep analysis of the results, it was considered that given that the expressions of the buckling correction factor proposed are a function of the relative slenderness at room 
temperature, it would be convenient to adopt the same criteria in this case and recommend the employment of a certain value of the effective length ratio depending on the relative slenderness of the column at room temperature.

Therefore, if the proposed method is used for computing the buckling fire resistance of a CFT column within a frame located at an intermediate floor, the adoption of the next values for the effective length is suggested:

- For $\bar{\lambda} \leq 0.5$, a value of $0.7 \mathrm{~L}$

- For $\bar{\lambda}>0.5$, a value of $0.5 \mathrm{~L}$

However, it is worth noting that the effective length ratio of 0.7 could be used in the design for all cases leading to conservative results.

With the combination of values proposed, the error given by the proposed method when compared to numerical simulations is shown in Fig. 13. The results obtained are more equilibrated that in the previous observations, with a mean value of $1.17(\sigma=0.15)$ lying on the safe side. It is important to note that the provisions given by the CEN-Horizontal Group Fire [28] have been contrasted and successful results have been obtained.

In Fig. 14, the comparison between the predicted values of the buckling fire resistance and the values given by the fiber beam model is shown. This graph complements the information about the accuracy of the final proposal since it includes the regression line and its coefficient of determination $\mathrm{R}^{2}$ for the prediction as recommended by $\mathrm{CEN}$ Horizontal Group Fire [28].

Regarding the range of application of the proposed method, it is important to take into account that it was developed for standard fire periods ranging from R30 to R120. Therefore, for this analysis and comparison only those specimens of the parametric study which presented a value of FRR between these limits were considered. 


\section{SUMMARY AND CONCLUSIONS}

In this paper, a study of the effects of axial and rotational restraints on the fire response of CFT columns was carried out. A validated fiber beam model was employed for the simulation of the CFT columns within a non-sway frame, where only the studied column was fire exposed and the rest of the structural members remained unheated. Next, a parametric analysis was performed considering the main factors affecting the problem where 360 frames were simulated. The cross-sectional geometry of the columns, the relative slenderness, the load level and the stiffness ratio were the aspects included in the study. The analysis of the results corroborated the conclusions presented by other researchers about the effects of the restraining frame. A positive action coming from the rotational restraint which modifies the boundary conditions of the heated column appears. On the contrary, a negative effect given by the restrained thermal elongation in the form of induced restraining forces also affects the column. If during a fire, the steel tube does not fail prematurely during the first stage when it is supporting the total load applied and it contacts back the concrete core, the beneficial effect coming from the redistribution of the internal forces is more noticeable and results in higher FRR.

As a last step, the current provisions given by Eurocode 4 Part 1.2 regarding the structural continuity of CFT columns in fire were analyzed, including the recommendation proposed by the UK National Annex to Eurocode 4. Thus, the study focused on the values of 0.5L and 0.7L. Predictions given by the general method of EN 1994-1-2 Clause 4.3.5.1 with $0.5 \mathrm{~L}$ tended to be unsafe, with $0.7 \mathrm{~L}$ being a value more recommendable in order to avoid unsafe results. Finally, a previously proposed simple method for circular CFT columns in fire was assessed, indicating that a general effective length ratio of 0.7 can be used in fire design and be considered conservative. A proposal for the effective length ratio 
was made according to this method showing good accuracy and following the guidelines proposed by the CEN-Horizontal Group.

\section{ACKNOWLEDGEMENTS}

The authors would like to express their sincere gratitude to both the Spanish "Ministerio de Ciencia e Innovación" and to the European Community through the FDEDER funds for the help provided to finance the Project BIA2012-33144. 


\section{REFERENCES}

[1] Ibañez C., Romero M.L., Hospitaler A. Fiber beam model for fire response simulation of axially loaded concrete filled tubular columns. Engineering Structures 2013; 56: 182-193.

[2] Ibañez C, Aguado JV, Romero ML, Espinos A, Hospitaler A. Fire design method for concrete filled tubular columns based on equivalent concrete core cross-section. Fire Safety Journal 2015; 78: 10-23.

[3] Espinos A, Romero M, Hospitaler A. Advanced model for predicting the fire response of concrete filled tubular columns. Journal of constructional steel research 2010; 66(89):1030-1046.

[4] Wang YC. The effects of structural continuity on the fire resistance of concrete filled columns in non-sway frames. Journal of Constructional Steel Research 1999; 50:177197.

[5] Bailey C. Effective lengths of concrete-filled steel square hollow sections in fire. Structures and Buildings 2000; 140(2):169-178.

[6] Yu M, Zha X, Ye J, Li Y. Fire responses and resistance of concrete-filled steel tubular frame structures. International Journal of Structural Stability and Dynamics 2010; 10 (2): $253-271$.

[7] Wang YC, Lennon T, Moore DB. The behavior of steel frames subject to fire. Journal of Constructional Steel Research 1995; 35: 291-322.

[8] Wang YC. Effects of structural continuity on the fire resistance design of steel columns in non-sway multi-storey frames. Fire Safety Journal 1997; 28: 101-116.

[9] Gomes F., Providencia e Costa P., Rodrigues J.P., Neves I. Buckling length of a steel column for fire design. Engineering Structures 2007; 29: 2497-2502. 
[10] Shepherd PG, Burgess IW. On the buckling of axially restrained steel columns in fire. Engineering Structures 2011; 33: 2832-2838.

[11] Correia AM, Rodrigues JP. 2012. Fire resistance of steel columns with restrained thermal elongation. Fire Safety Journal 50: 1-11.

[12] Couto C, Vila Real P, Lopes N, Rodrigues JP. 2013. Buckling analysis of braced and unbraced steel frames exposed to fire. Engineering Structures 49: 541-559.

[13] CEN. EN 1994-1-2, Eurocode 4: Design of composite steel and concrete structures, Part 1.2: General rules - Structural fire design. Brussels, Belgium: Comité Européen de Normalisation; 2005.

[14] Filippou F.C. and Constantinides. FEDEASLab. Getting Started Guide and Simulation Examples. Technical Report NEESgrid-2004-22, Berkeley, CA: Civil and Environmental Eng. Dept. University of California at Berkeley, 2004.

[15] CEN. EN 1991-1-2, Eurocode 1: Actions on structures, Part 1.2: General actions Actions on structures exposed to fire. Brussels, Belgium: Comité Européen de Normalisation; 2002.

[16] ISO (International Standards Organization). ISO 834: Fire resistance tests, elements of building construction. Switzerland: International Standards Organisation; 1980.

[17] Ding J, Wang YC. Realistic modelling of thermal and structural behavior of unprotected concrete filled tubular columns in fire. Journal of Constructional Steel Research 2008; 64:1086-1102.

[18] Spacone E., Ciampi V., Filippou F.C. Mixed formulation of nonlinear beam finiteelement. Computers \& Structures 1996; 58(1):71-83.

[19] Lie TT. Fire resistance of circular steel columns filled with bar-reinforced concrete. Journal of Structural Engineering-ASCE 1994; 120(5):1489-1509. 
[20] CEN. EN 1992-1-2, Eurocode 2: Design of concrete structures, Part 1.2: General rules - Structural fire design. Brussels, Belgium: Comité Européen de Normalisation; 2004.

[21] CEN. EN 1993-1-2, Eurocode 3: Design of steel structures, Part 1.2: General rules Structural fire design. Brussels, Belgium: Comité Européen de Normalisation; 2005.

[22] Hong S, Varma AH. Analytical modeling of the standard fire behavior of loaded CFT columns. Journal of Constructional Steel Research 2009; 65:54-69.

[23] NA to BS EN 1994-1-2:2005, UK National Annex for Eurocode 4: Design of composite steel and concrete structures, Part 1.2: General rules - Structural fire design. The British Standards Institution; 2008.

[24] Pires T., Rodrigues J.P., Silva J. Fire resistance of concrete filled circular hollow columns with restrained thermal elongation. Journal of Constructional Steel Research 2012; 77: 82-94.

[25] Espinos A., Romero M.L., Hospitaler A. Simple calculation model for evaluating the fire resistance of unreinforced concrete filled tubular columns. Engineering Structures 2012; 42: 231-244.

[26] Lennon T, Moore DB, Wang YC, Bailey CG. 2007. Designers' guide to EN 1991-1-2, EN 1992-1-2, EN 1993-1-2 and EN 1994-1-2. Thomas Telford Limited.

[27] CEN. EN 1994-1-1, Eurocode 4: Design of composite steel and concrete structures, Part 1.1: General rules and rules for buildings. Brussels, Belgium: Comité Européen de Normalisation; 2004.

[28] CEN-TC-250-Horizontal Group Fire. Document 99/130. Eurocodes-Fire Parts. Proposal for a methodology to check the accuracy of assessment methods.. November 1999 


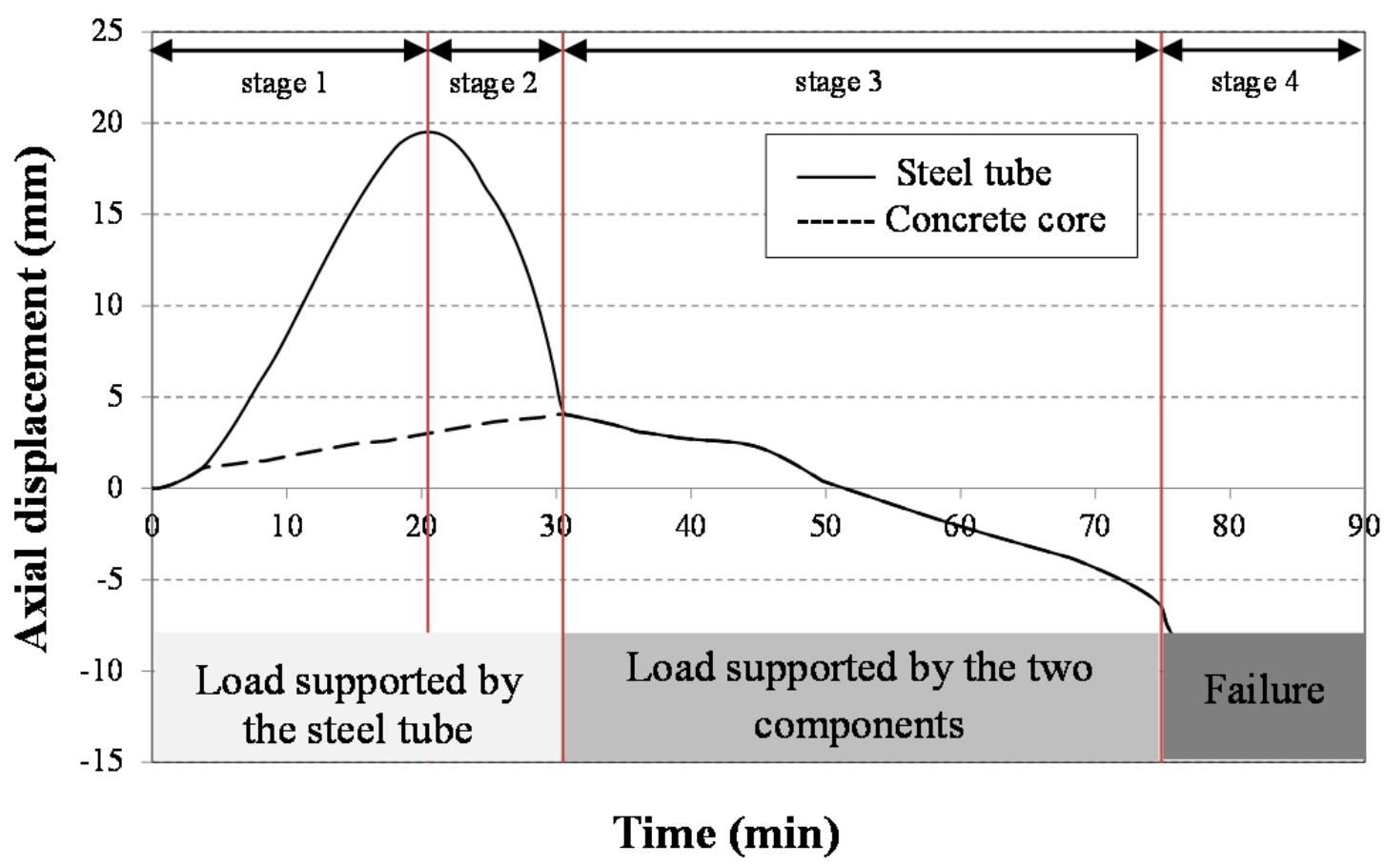

Fig. 1. Typical behavior of a CFT column subjected to elevated temperatures.

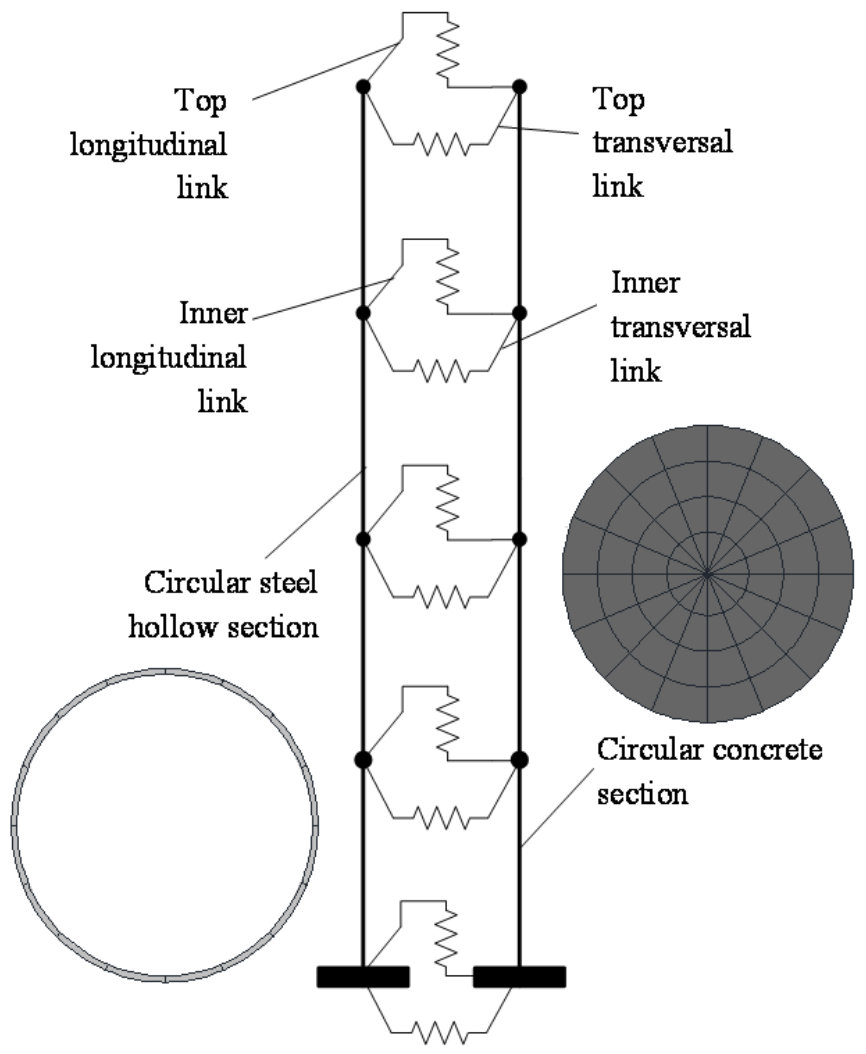

Fig. 2. Parallel model scheme [1]. 


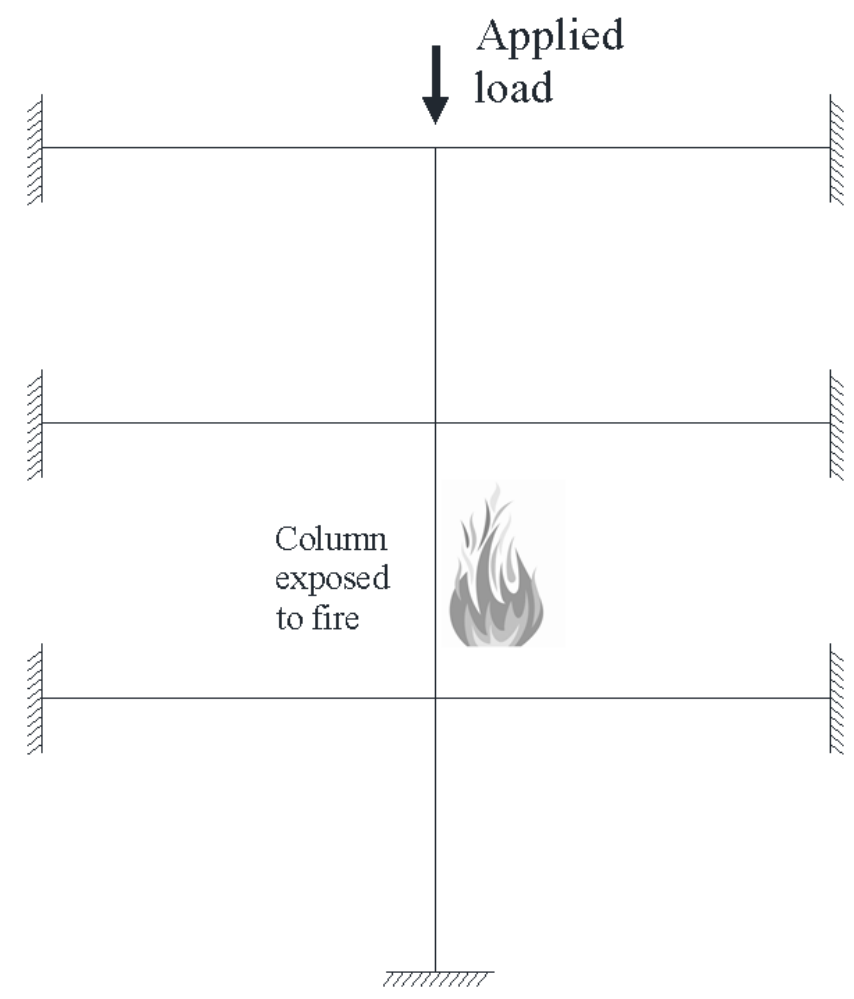

Fig. 3. Subframe scheme used in the analysis.

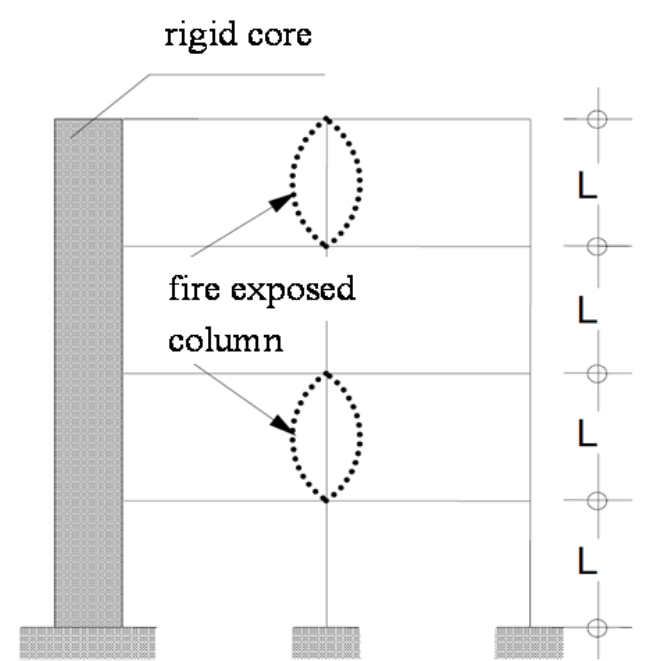

(a)

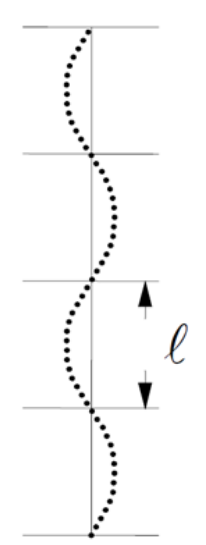

(b)

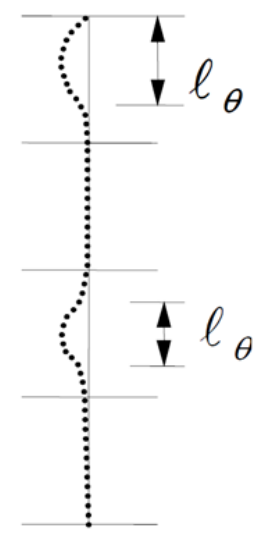

(c)

(a) section through the building

(b) deformation mode at room temperature

(c) deformation mode at elevated temperature

Fig. 4. Structural behavior of columns in braced frames [13]. 


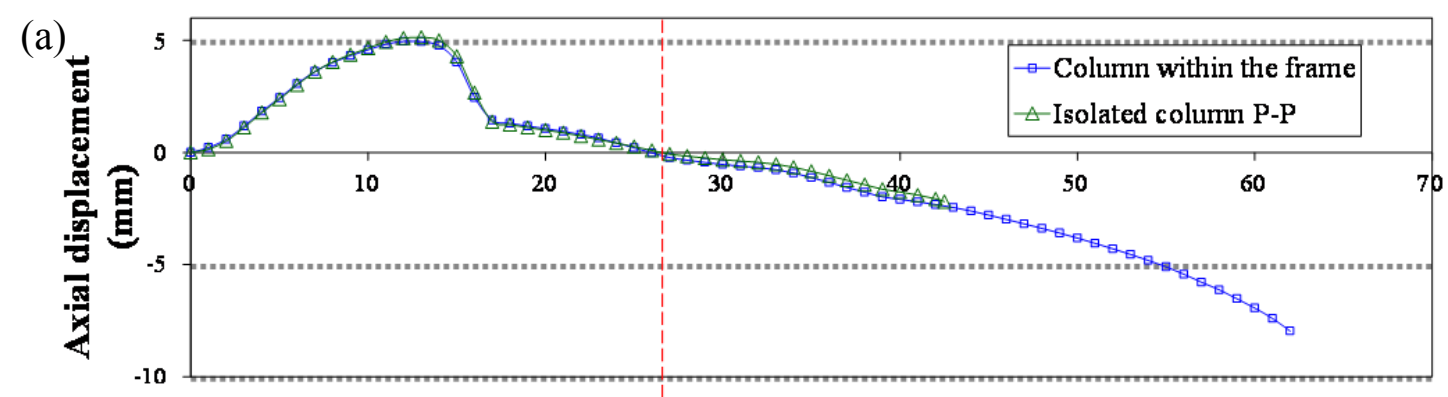

(b)

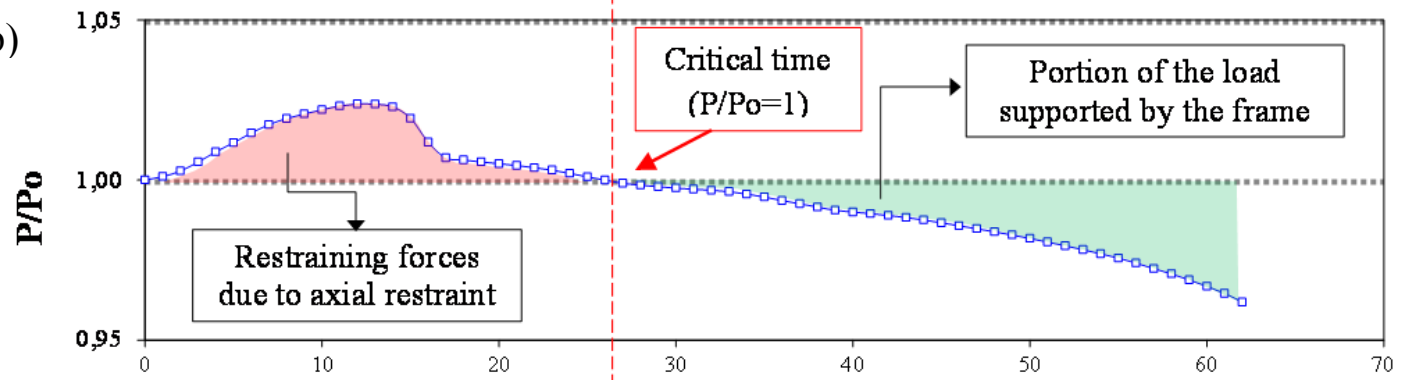

(c)

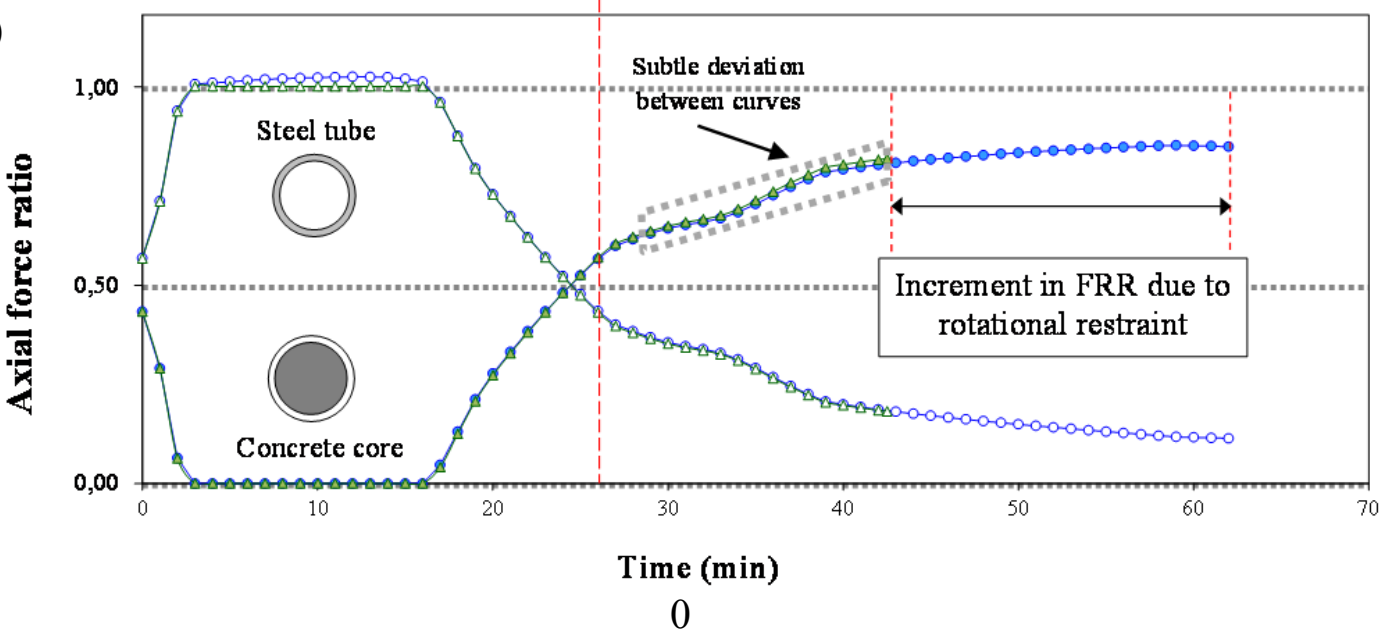

Fig. 5. Fire response of specimen C193-5-1351-0.3 $\mu=0.3 \alpha=0.5$. 
(a)

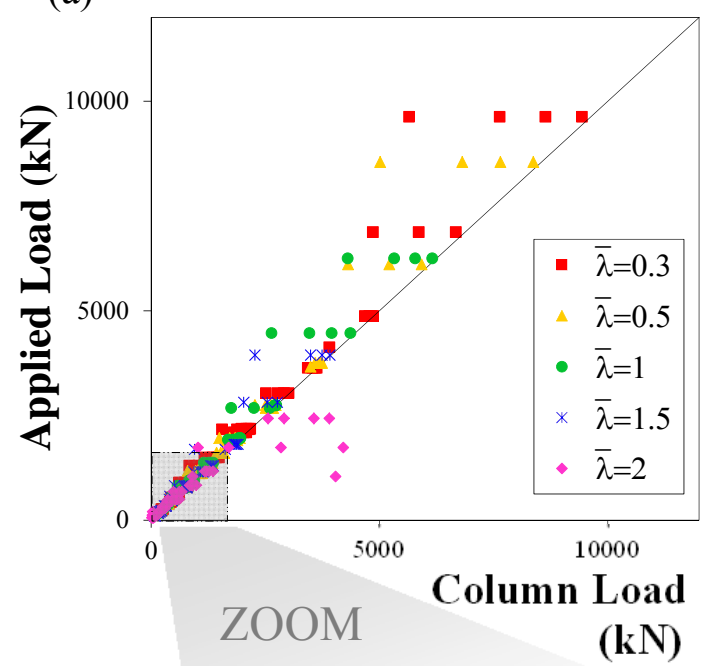

(c)

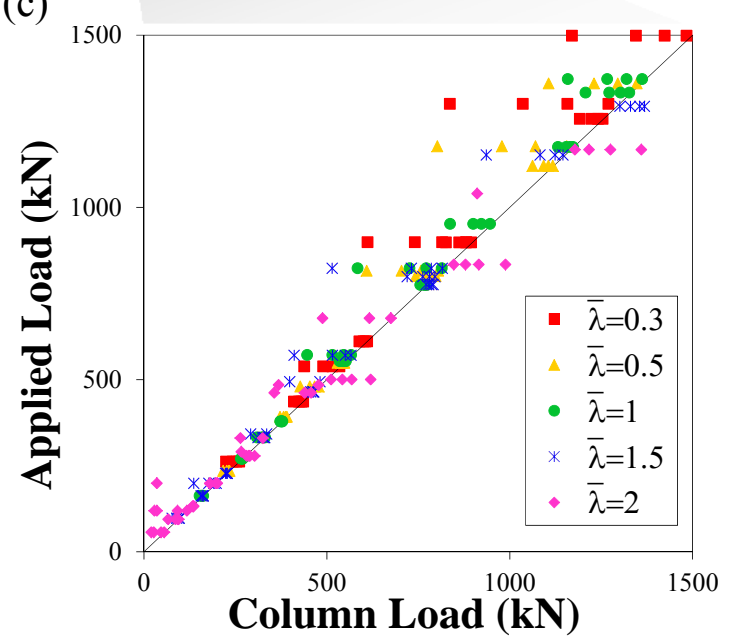

(b)

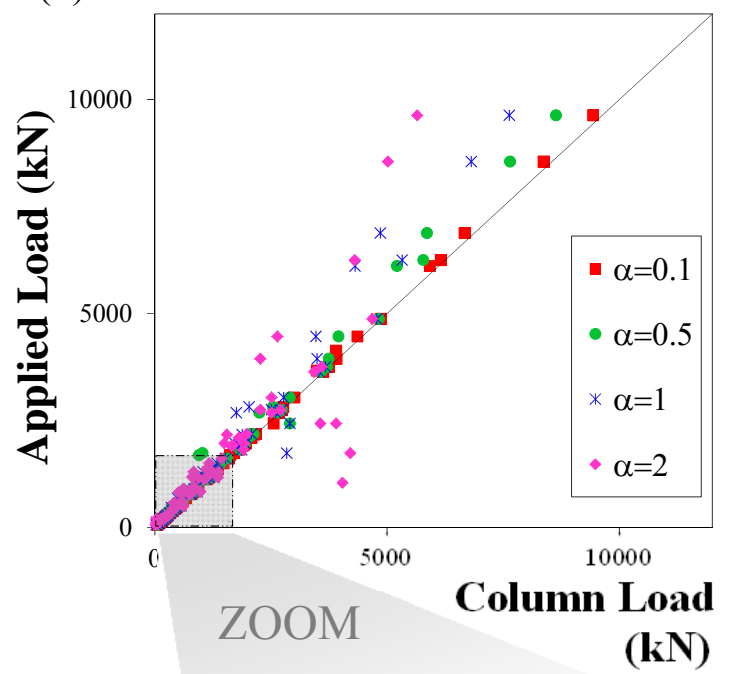

(d)

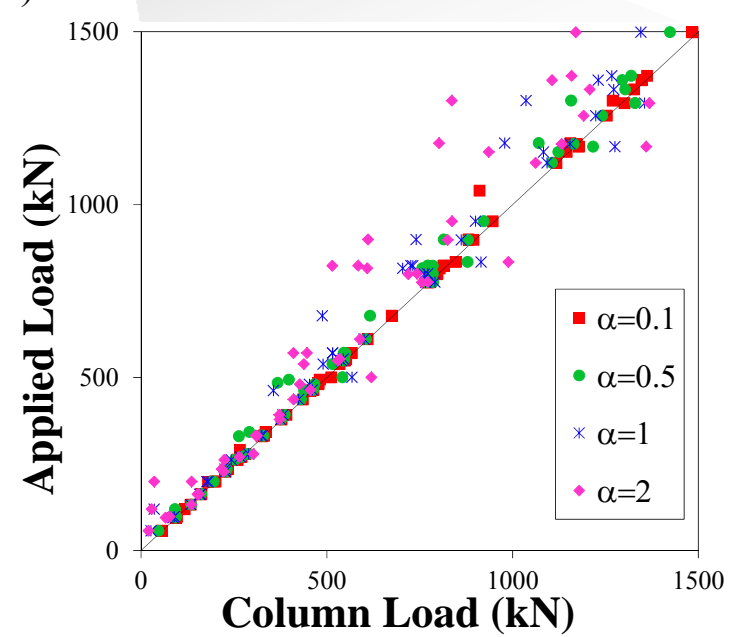

Fig. 6. Comparison of the applied load and the buckling fire resistance of the columns within frames: (a)(c) by relative slenderness; (b)(d) by stiffness ratio. 


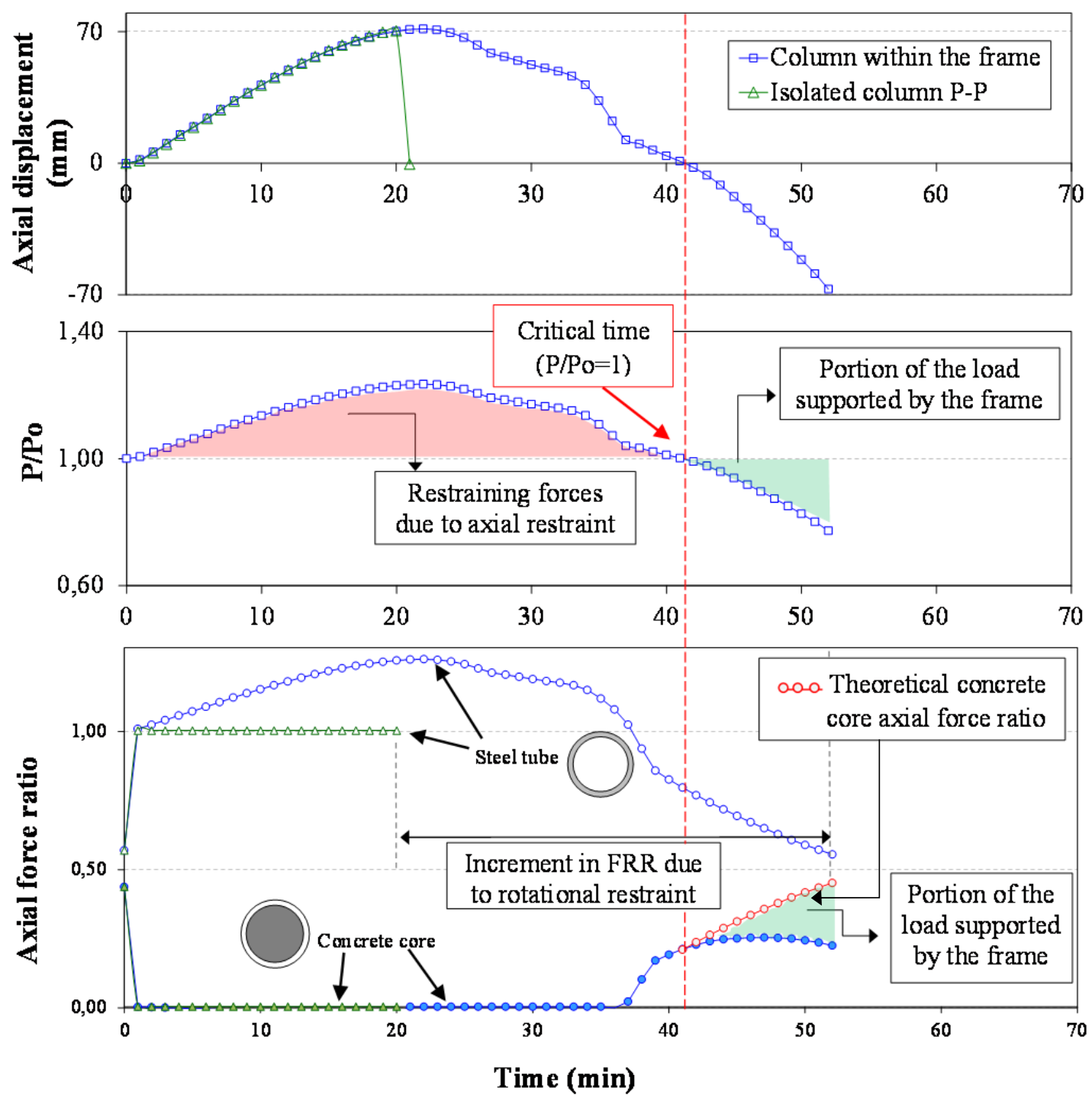


(a)

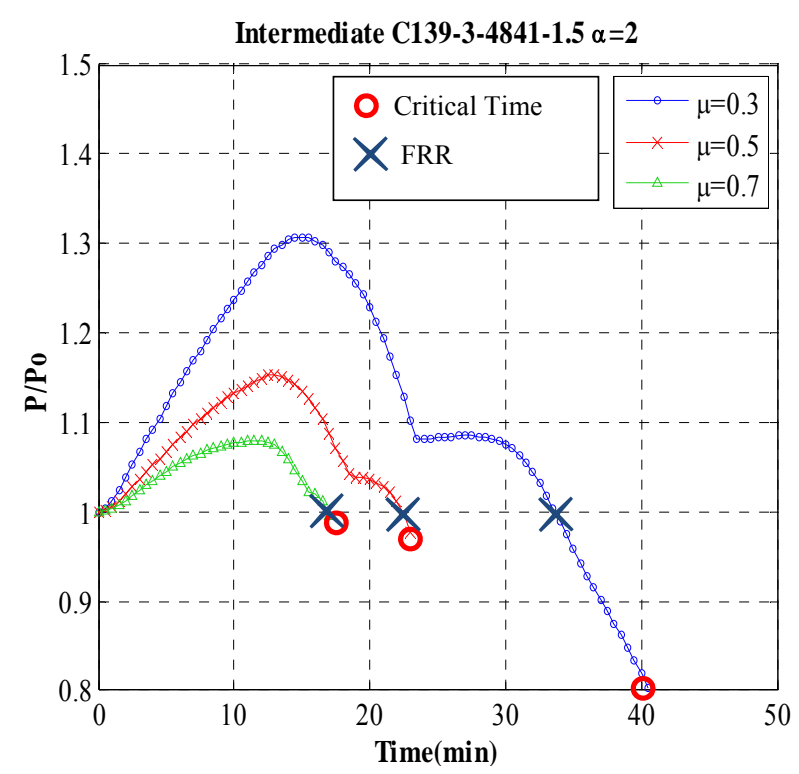

(c)

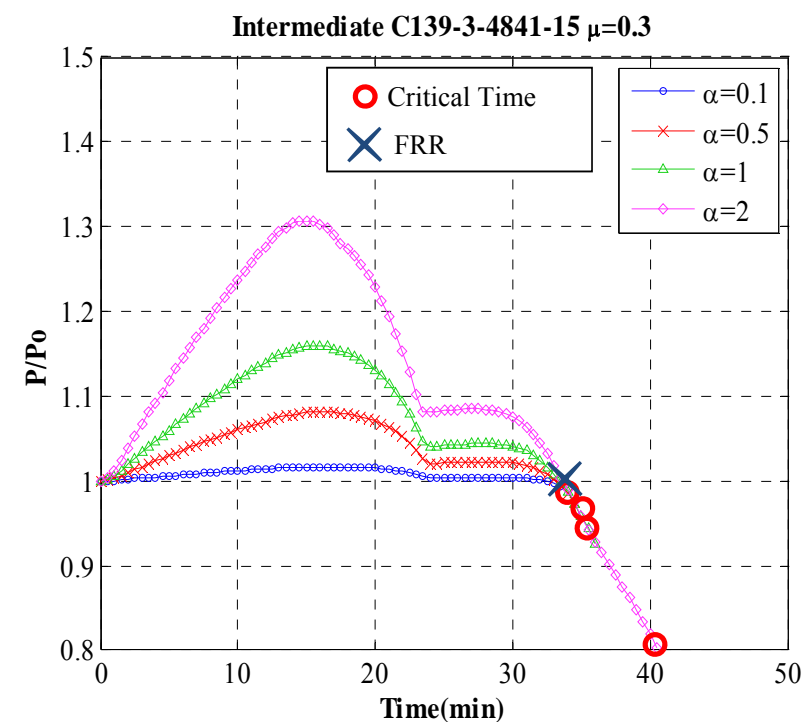

(b)

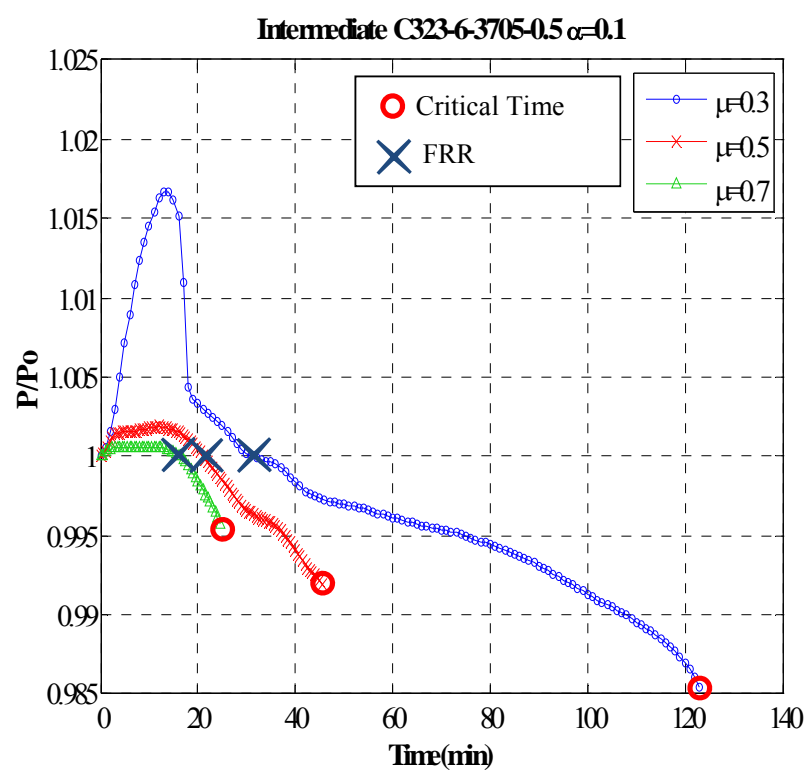

(d)

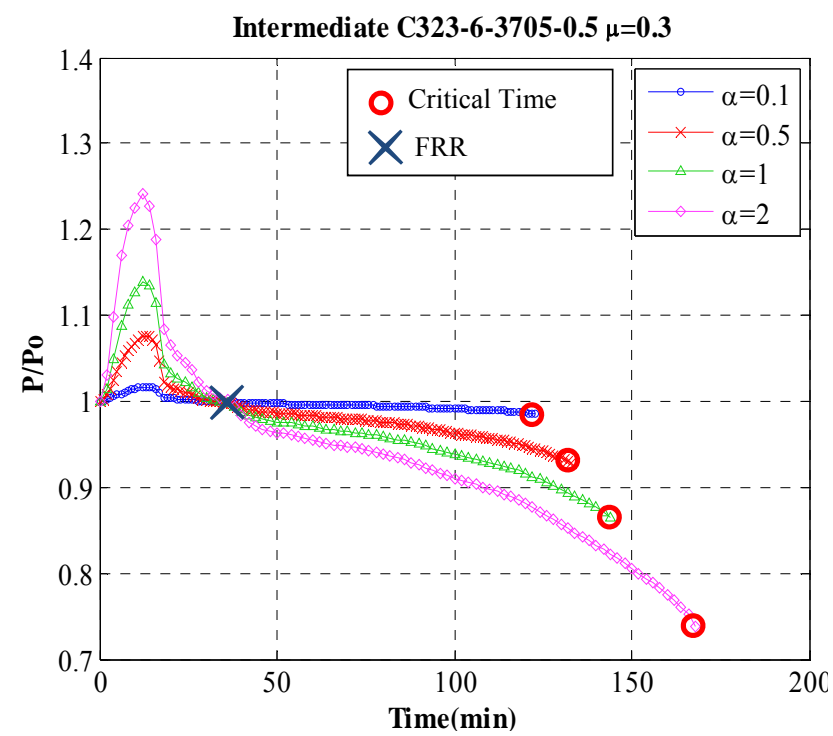

Fig. 8. Influence on the restraining forces of: (a) (b) load level; (c) (d) stiffness ratio. 
(a)

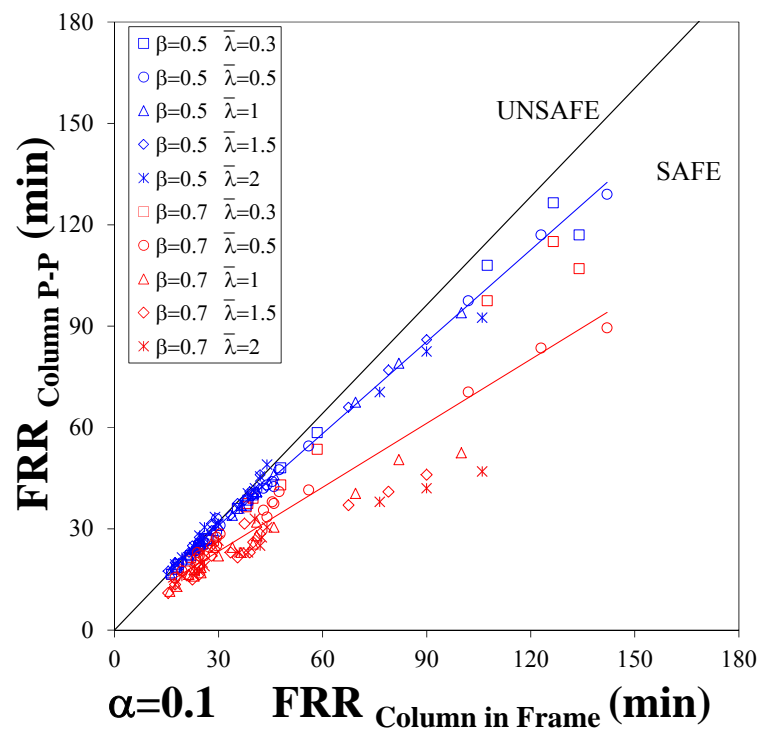

(c)

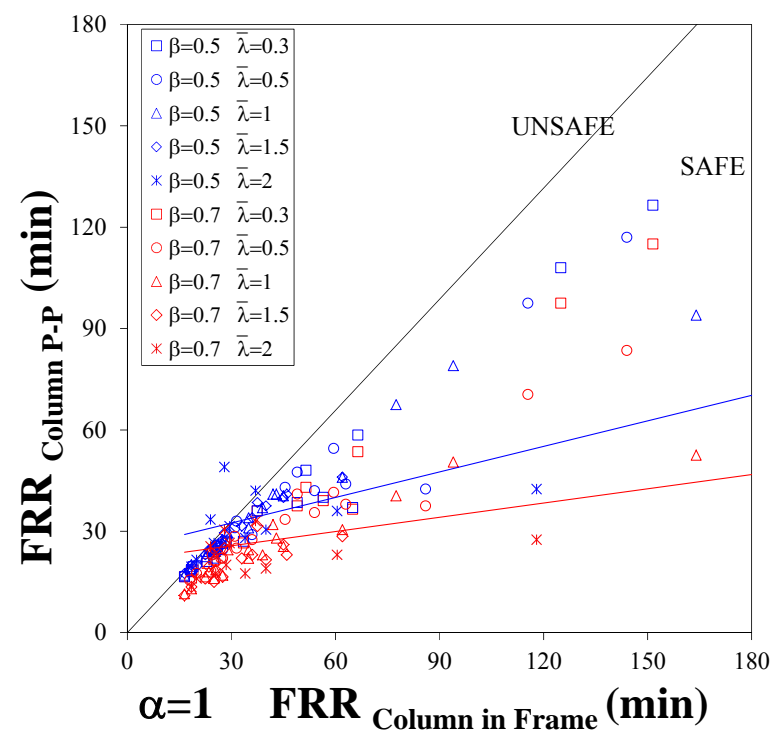

(b)

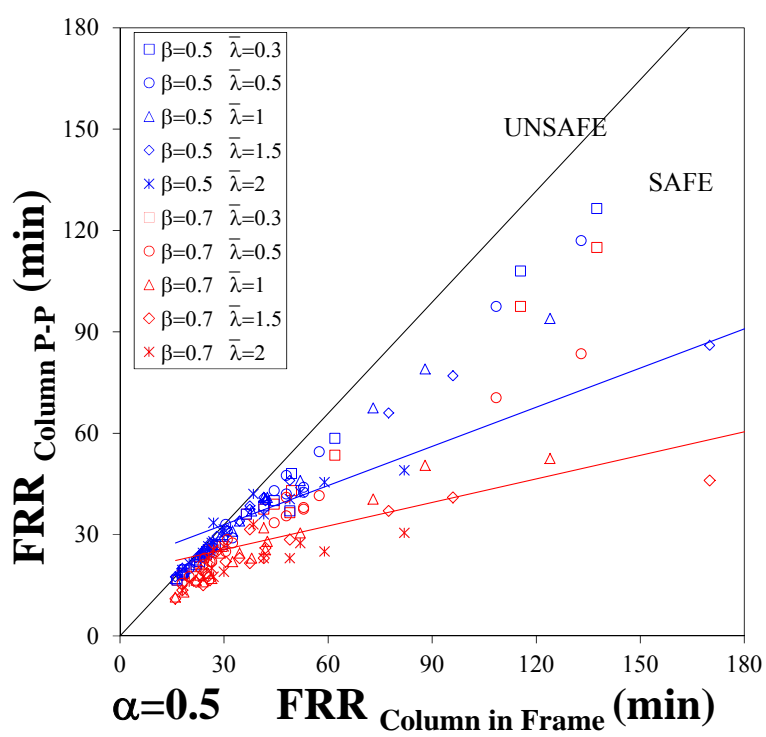

(d)

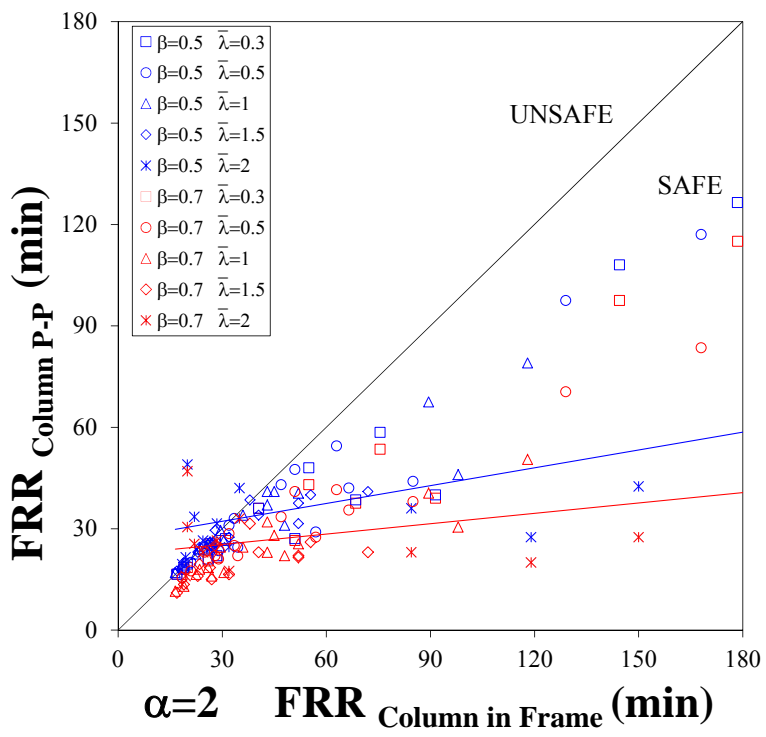

Fig. 9. Comparison of the FRR obtained by the column within the frame with the FRR of isolated P-P columns under different effective lengths. 


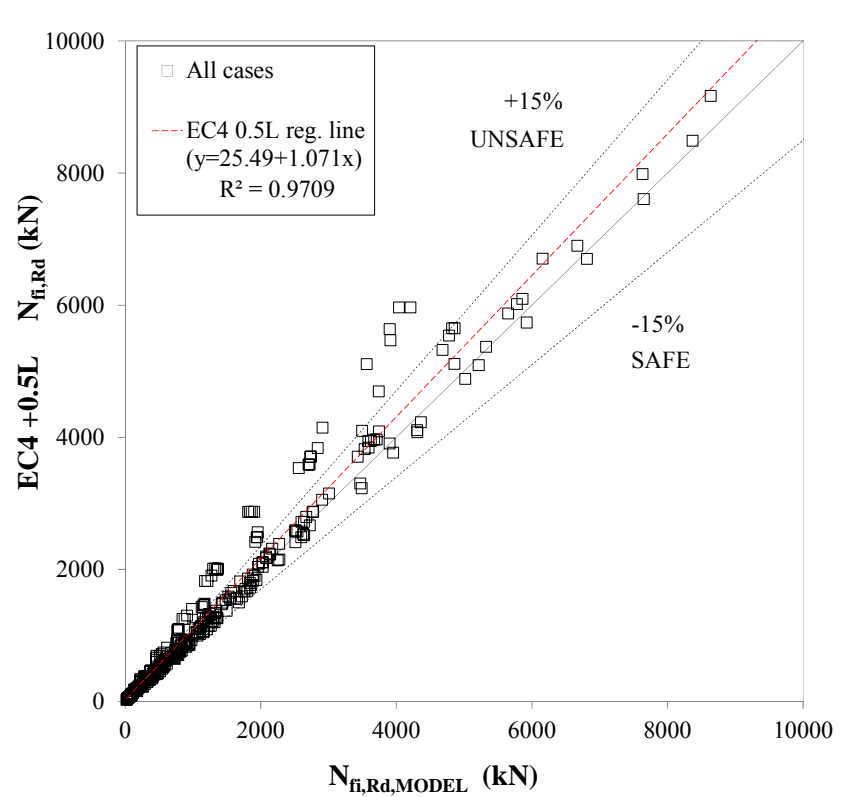

(a) Comparison of predictions given by EC4 $+0.5 \mathrm{~L}$ and numerical simulations.

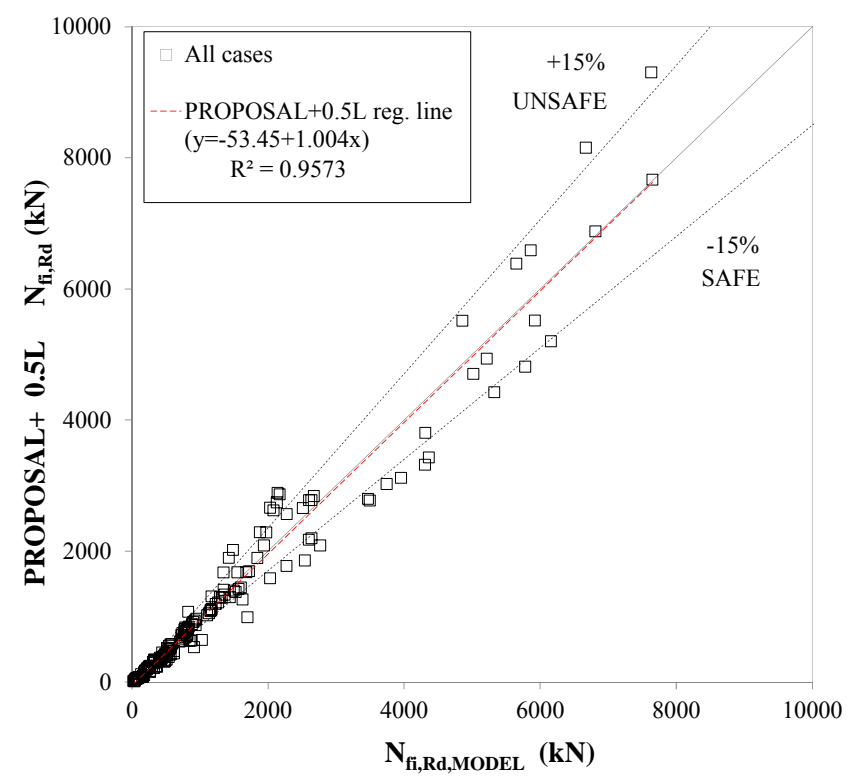

(c) Comparison of predictions given by PROPOSAL $+0.5 \mathrm{~L}$ and numerical simulations.

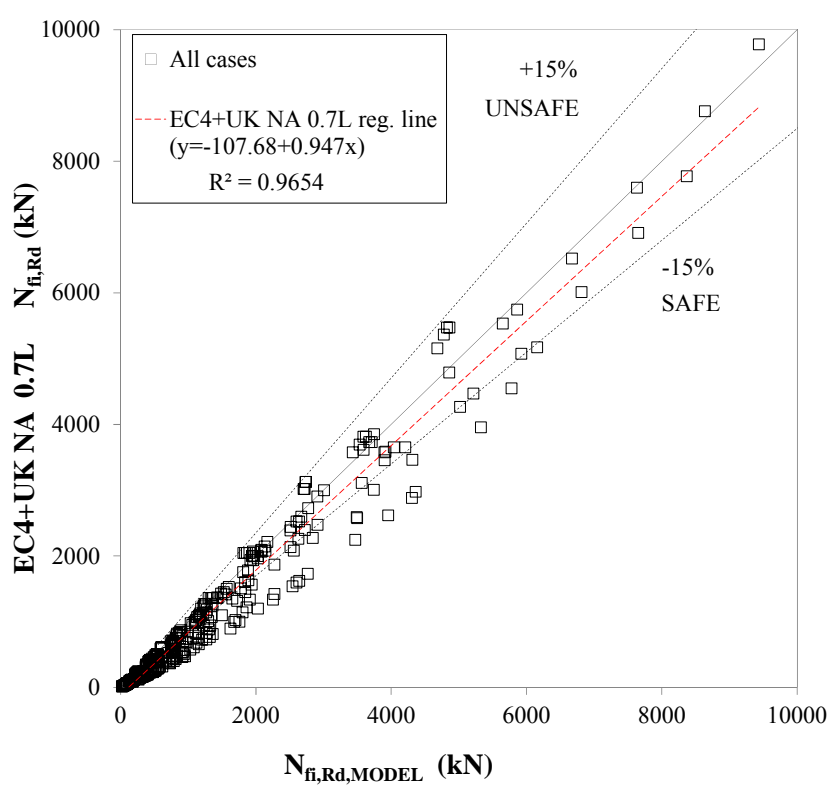

(b) Comparison of predictions given by EC4+UK NA 0.7L and numerical simulations.

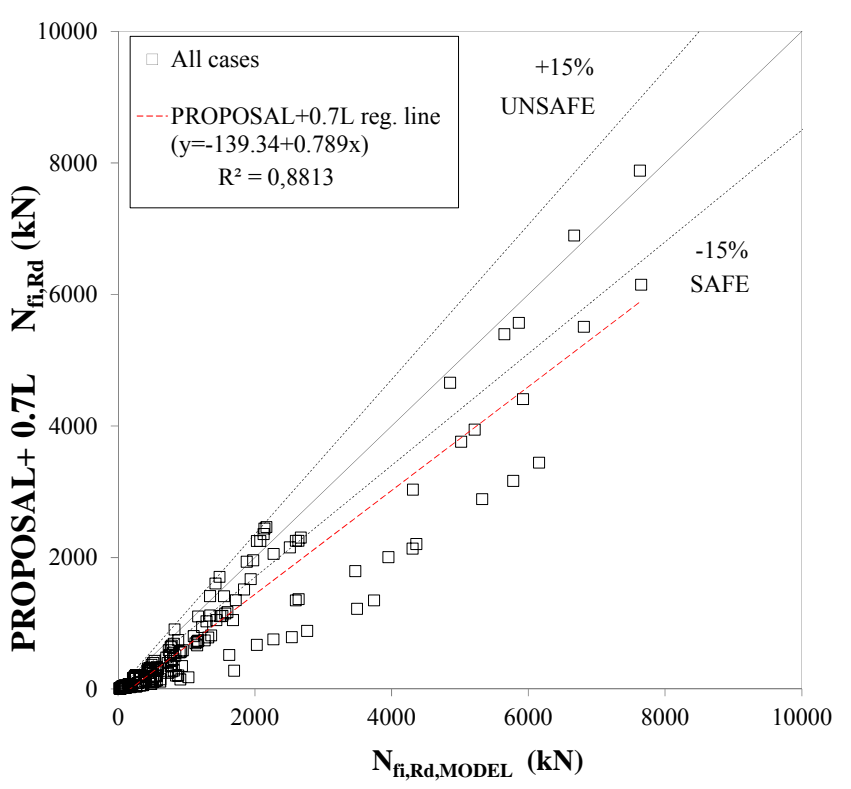

(d) Comparison of predictions given by PROPOSAL $+0.7 \mathrm{~L}$ and numerical simulations.

Fig. 10. Comparison of predictions given by different methods and numerical simulations. 


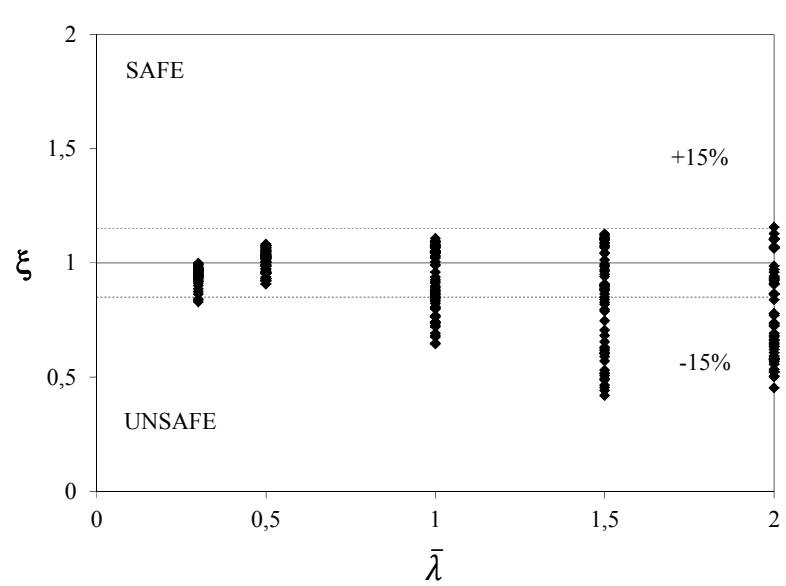

(a) Relative error. Predictions given by EC4 + $0.5 \mathrm{~L}$ and numerical simulations.

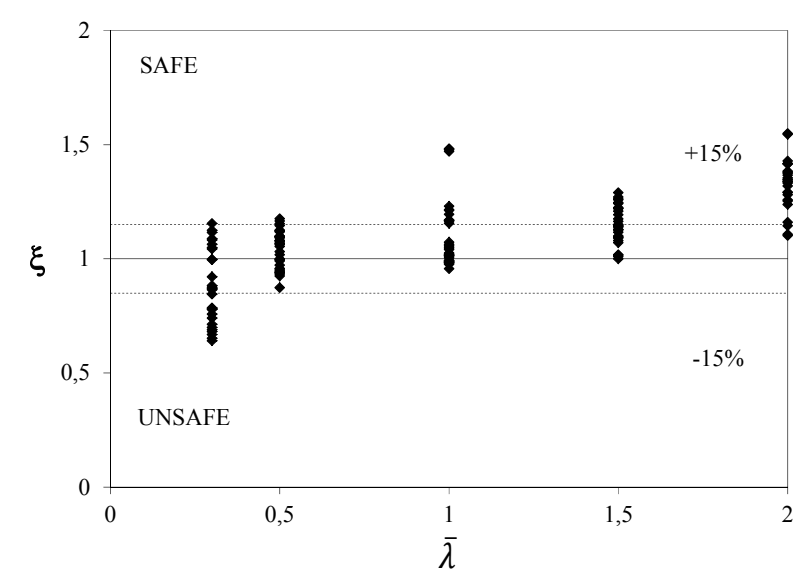

(c) Relative error. Predictions given by PROPOSAL $+0.5 \mathrm{~L}$ and numerical simulations.

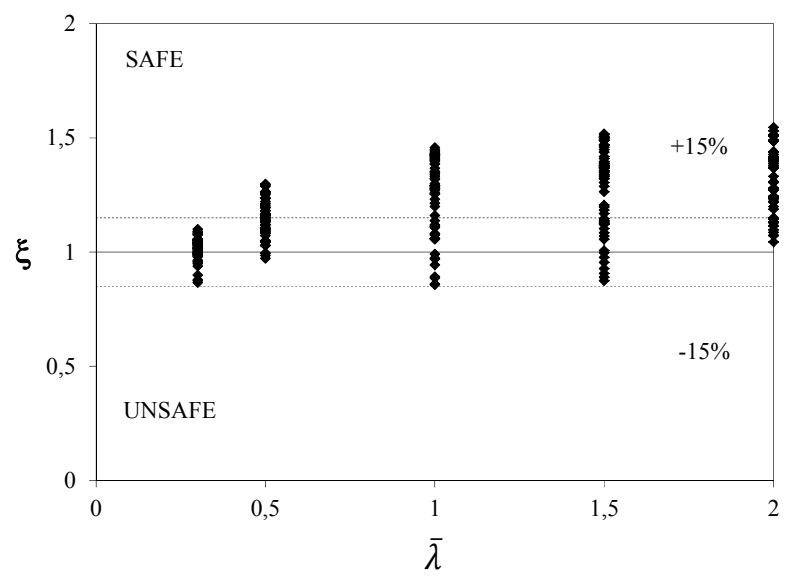

(b) Relative error. Predictions given by EC4+UK NA 0.7L and numerical simulations.

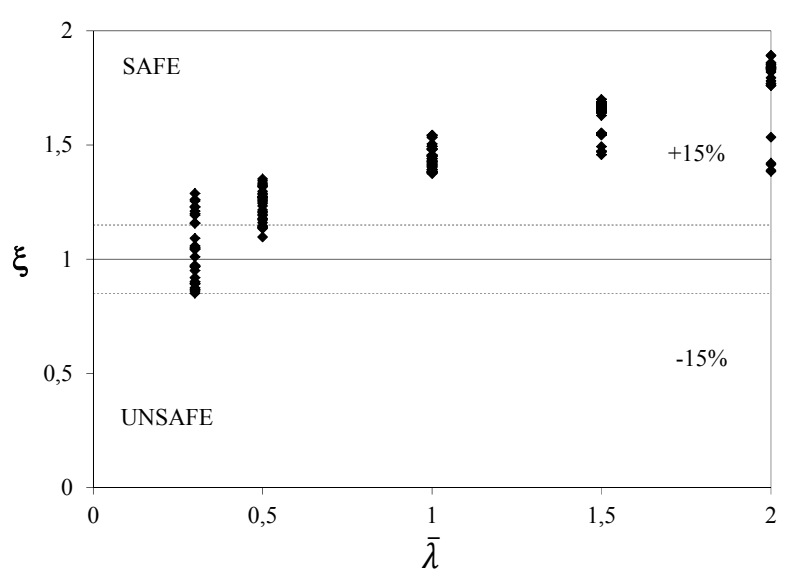

(d) Relative error. Predictions given by PROPOSAL $+0.7 \mathrm{~L}$ and numerical simulations.

Fig. 11. Comparison of predictions given by different methods and numerical simulations. 


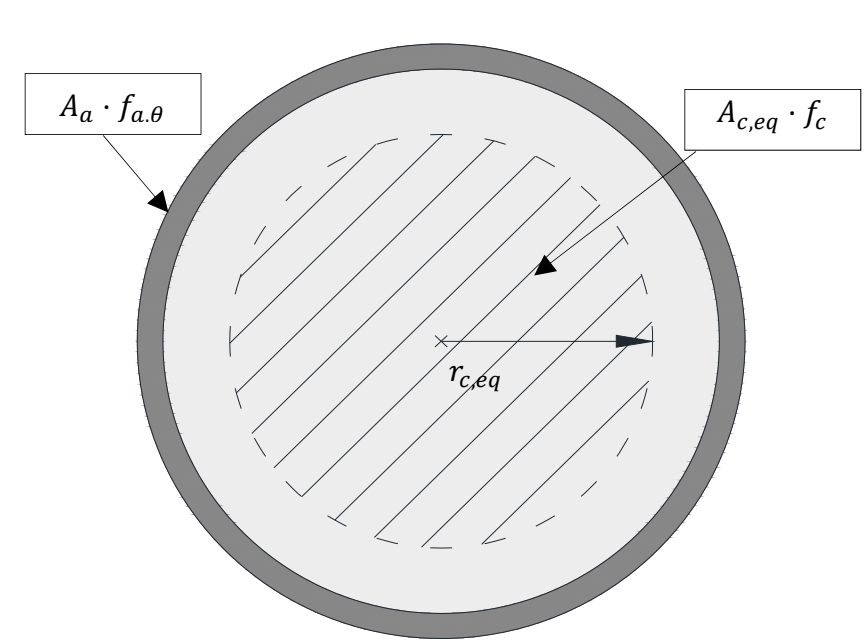

(a) Equivalent concrete core section according to the method proposed

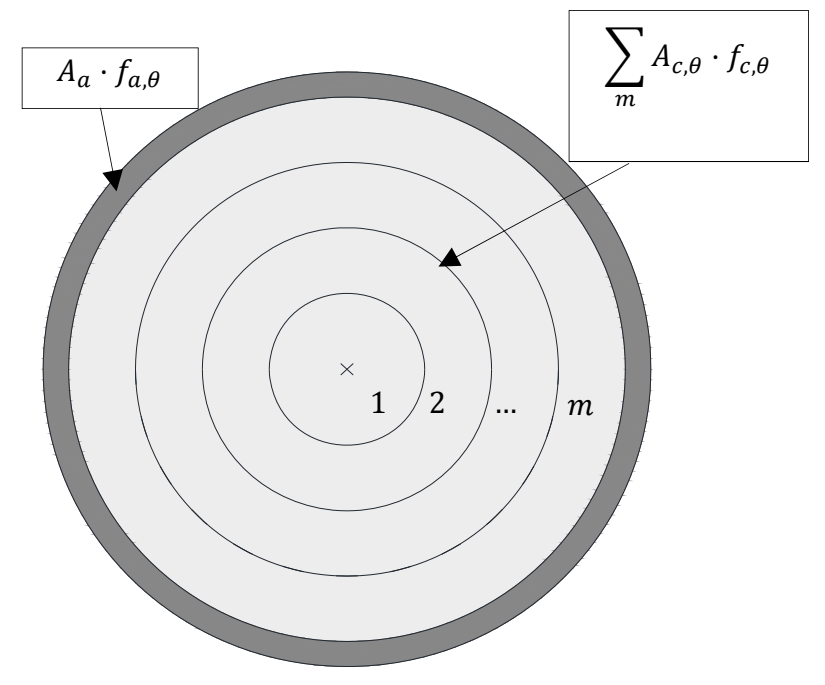

(b) Concrete core divided in layers according to $\mathrm{EN}$ 1994-1-2 [1]

Fig. 12. Schemes for CFT columns cross sections.

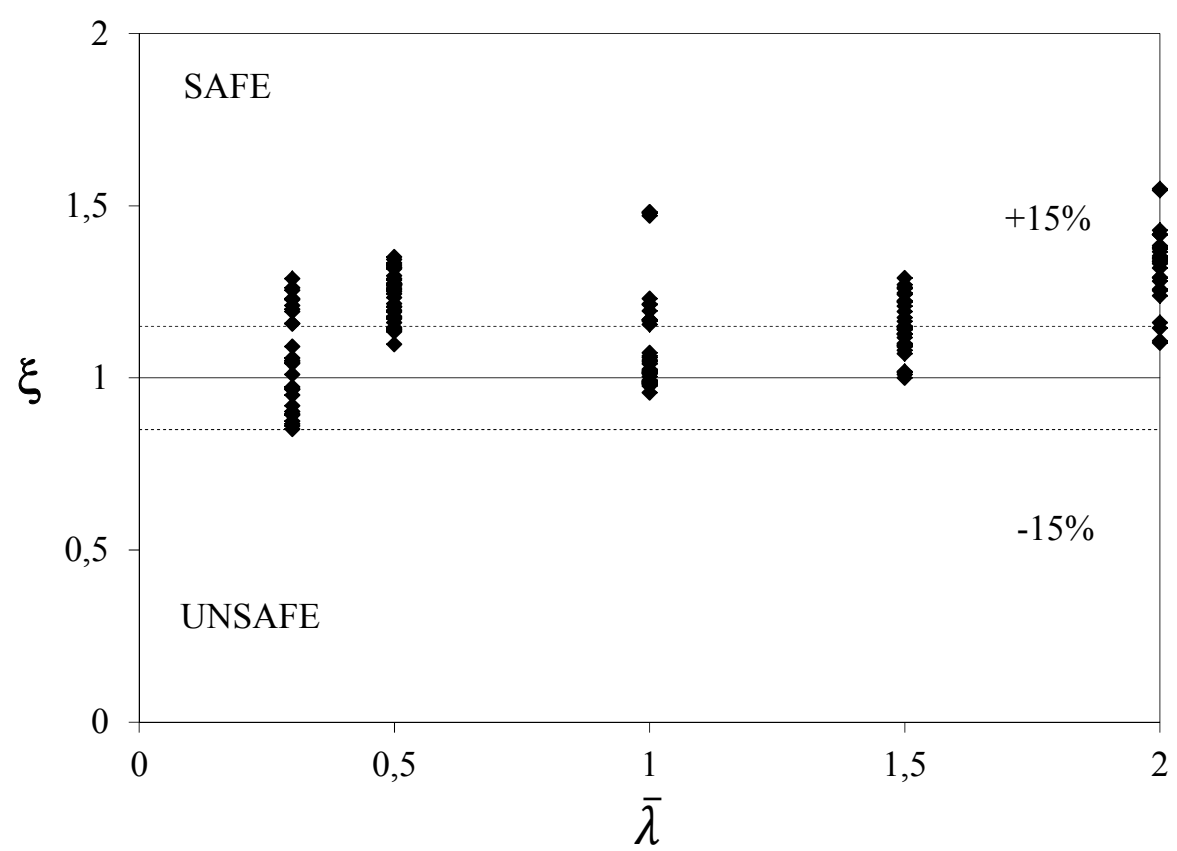

Fig. 13. Relative error. Comparison between the predictions given by the final proposal and numerical simulations. 


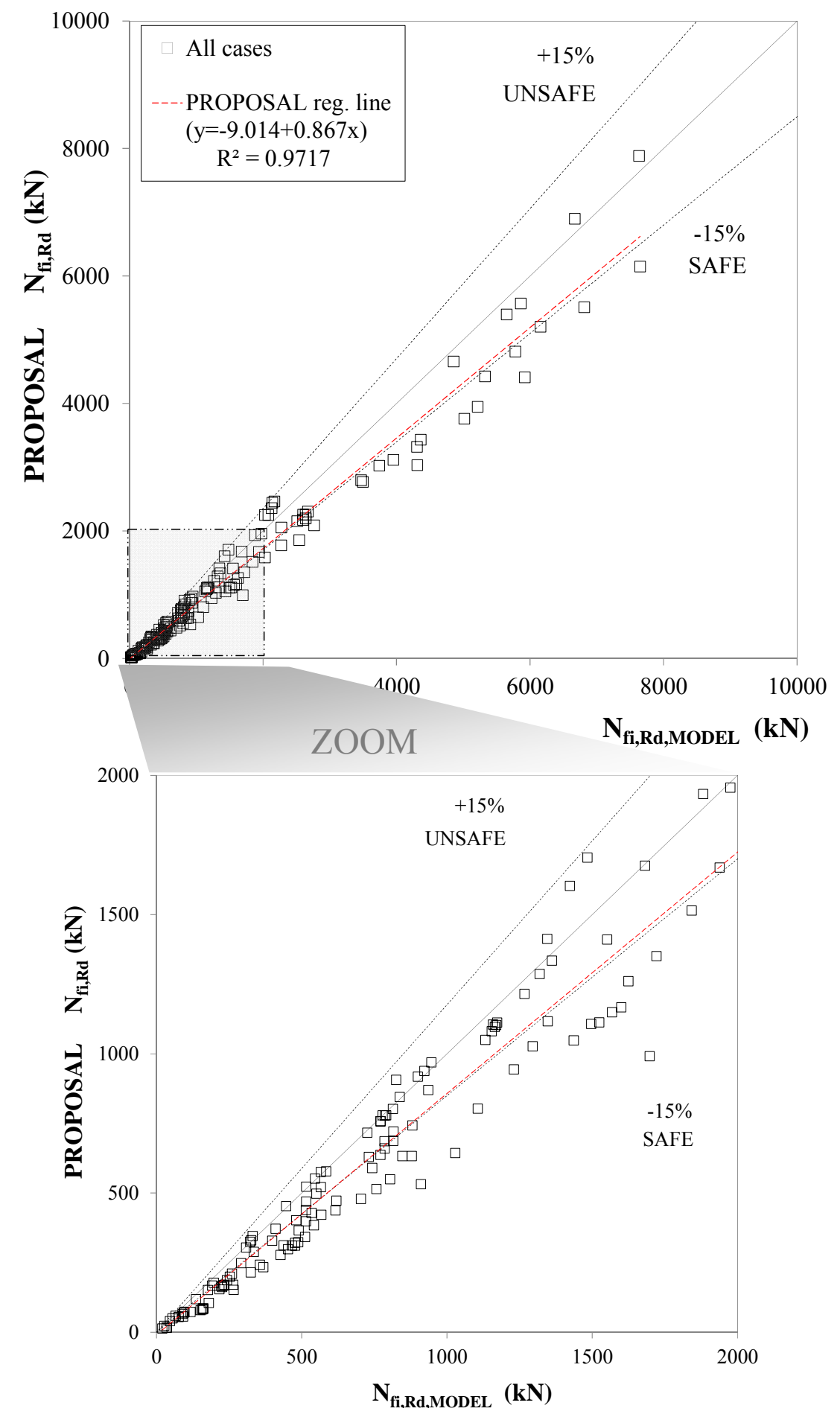

Fig. 14. Comparison between the predictions given by the final proposal and numerical simulations. 
Table 1.Summary of the cases included in the parametric analysis

\begin{tabular}{c|c|c|c|c|c}
\hline $\begin{array}{c}\text { Parameters } \\
\text { studied }\end{array}$ & $\begin{array}{c}\boldsymbol{D} \\
\mathbf{( m m )}\end{array}$ & $\begin{array}{c}\boldsymbol{t} \\
\mathbf{( m m )}\end{array}$ & $\bar{\lambda}$ & $\boldsymbol{\mu}$ & $\boldsymbol{\alpha}$ \\
\hline & 139.7 & 3.2 & & & \\
Adopted & 193.7 & 5 & & & \\
values & 273 & $5 ; 16$ & $0.3 ; 0.5 ; 1 ; 1.5 ; 2$ & $0.3 ; 0.5 ; 0.7$ & $0.1 ; 0.5 ; 1 ; 2$ \\
& 323.9 & 6.3 & & & \\
& 508 & 16 & & & \\
\hline
\end{tabular}




\section{LIST OF FIGURE CAPTIONS}

Fig. 1 . Typical behavior of a CFT column subjected to elevated temperatures.

Fig. 2 . Parallel model scheme [1].

Fig. 3 . Subframe scheme used in the analysis.

Fig. 4 . Structural behavior of columns in braced frames [13].

Fig. 5 . Fire response of specimen C193-5-1351-0.3 $\mu=0.3 \alpha=0.5$.

Fig. 6 . Comparison of the applied load and the buckling fire resistance of the columns within frames: (a)(c) by relative slenderness; (b)(d) by stiffness ratio.

Fig. 7 . Fire response of specimen C193-5-9010-2 $\mu=0.3 \alpha=0.5$.

Fig. 8 . Influence on the restraining forces of: (a) (b) load level; (c) (d) stiffness ratio.

Fig. 9 . Comparison of the FRR obtained by the column within the frame with the FRR of isolated P-P columns under different effective lengths.

Fig. 10 . Comparison of predictions given by different methods and numerical simulations.

Fig. 11 . Comparison of predictions given by different methods and numerical simulations.

Fig. 13 . Relative error. Comparison between the predictions given by the final proposal and numerical simulations.

Fig. 14 . Comparison between the predictions given by the final proposal and numerical simulations.

\section{LIST OF TABLE CAPTIONS}

Table 1. Summary of the cases included in the parametric analysis 